\title{
A Predictive Solution for Engineering Calculations on a Full Scale Aircraft Post-Crash Fire
}

\author{
HY Wang ${ }^{1 *}$ and GD Wang ${ }^{2}$ \\ ${ }^{1}$ Institut $P$, Fluides-Thermique-Combustion, Universite de Poitiers, France \\ ${ }^{2}$ Civil Aviation University of China, China
}

\begin{abstract}
Large Eddy Simulation combined with an Eddy Dissipation Concept (EDC) combustion model shows the feasibility for simulations of a full scale aircraft immersed within a large aviation-fuel fire in a moving fluid medium. Coupling between the condensed fuel and gas phases allows investigating the roles of the wind condition on the burning rate of condensed fuel, and consequently, the heat release rate. The prediction indicates that interaction between aircraft and fire environment combined with the influence of wind conditions (speed and direction) affects dramatically dispersion of the smoke products, such as carbon monoxide and soot. Increase of the wind speed results in an alteration of the distribution of the incident heat fluxes to the surface of the engulfed aircraft. The highest heat flux occurs on the windward side of the aircraft for the wind speed below $2 \mathrm{~m} / \mathrm{s}$, but on the leeward side of the fuselage for the wind speed beyond $5 \mathrm{~m} / \mathrm{s}$. In the presence of wind, the aircraft orientation relative to the external post-crash fire has also an important impact on the heat flux and temperature distributions on the fuselage skin. Elongation of the flame towards the aircraft in the downstream direction becomes the strongest when the aircraft moving direction is perpendicular to the crosswind in particular for the wind speed beyond $5 \mathrm{~m} / \mathrm{s}$.
\end{abstract}

\section{Keywords}

Aircraft fire, Fire models, Toxic product, Heat flux, Crosswind, Aviation-Fuel

\section{Introduction}

Fuel is carried in different fuel tanks, all of which are integrally distributed within the aircraft structure. A general feature of most, uneven temperature distributions can occur, producing areas of locally relatively high temperatures. Such local effects can also be produced by different causes, such as a distorted fuel nozzle, flow pattern, distortion of the dimensions of the can or cooling airflow disturbance caused by repairs or faulty design/ manufacture. The aircraft is fitted with separate fire and overheat detection systems designed to alert the crew to excessive temperatures within the engine nacelles. The engine failure may be caused by an explosive rupture of the combustion chamber outer case. The rupture imme- diately causes the engine to run down. The fire ignites when fuel from the punctured wing tank access panel comes into contact with combustion gases escaping from the damaged engine. Although the wind has strength so slight that it has a relatively insignificant factor in terms of aircraft handling-there is a powerful body of evidence which clearly shows that the influence of the wind on the accident is paramount. Not only does it drive the static fire plume against and beneath the hull, making a more rapid penetration of the aluminium (B747 family) alloy fuselage skins inevitable, it creates an aerodynamic pressure field around the fuselage which, once doors and exits have been opened on the side opposite to the fire, induced the products of the external fire into and down the length of the cabin interior. In

${ }^{*}$ Corresponding author: HY Wang, Institut $P$, Fluides-Thermique-Combustion, CNRS, ENSMA, Universite de Poitiers, BP 40109, F86961 Futuroscope Chasseneuil Cedex, France, E-mail: wang@ensma.fr

Received: January 06, 2017: Accepted: April 05, 2017: Published: April 08, 2017

Copyright: (c) 2017 Wang HY, et al. This is an open-access article distributed under the terms of the Creative Commons Attribution License, which permits unrestricted use, distribution, and reproduction in any medium, provided the original author and source are credited. 
turn, some interior materials ignite leading to the development of a fire inside the cabin. Conditions in the cabin will be controlled by the combined influence of the wind and the various openings in the fuselage. The fuselage assembly including skin, thin thermo-acoustic insulation material, air layer and cabin wall, can be considered as a barrier to the fire penetration into the cabin. Under an external heat flux from fire, burn-through time of an aluminium alloy fuselage depends mainly on its melting point $\left(650-700{ }^{\circ} \mathrm{C}\right)$ and its thickness $(2-3 \mathrm{~mm})$. During a post-crash fire, knowledge of burn-through time of the fuselage, which should not occur within 3 minutes, is of interest to guide the evacuation strategy. Moreover, regarding the new generation of aircraft (A350 family), the substitution of aluminium alloy fuselage by flammable composite material may induce large fuel release, leading to more intensive fire. In general, burn-through of a composite fuselage with a thickness of 3-5 mm does not occur within 3 minutes thanks to the material composition of resin/carbon fibres. The decision making process regarding fire safety in aviation company depends increasingly on numerical simulations for estimating the external heat flux which is strongly associated with the burning rate of the liquid pool fire.

Intensive research has been carried over decades on the burning rate of the pool fires [1-5], though only a small proportion of the work has looked specifically on CFD work [6,7] in which the condensed fuel and gas phases are coupled. The burning rate of free pool fire can be estimated with a simple correlation [1] that requires only the knowledge of fuel properties. The empirical correlation of Peatross [2] for fuel mass loss rate is limited to the case where the heat fluxes from low gas and wall temperature can be negligible. The theoretical model developed by Utiskul [3] allows to predict mass loss rate solely for small-scale pool fire experiments, because flame radiation heat feedback to the liquid surface was neglected. The study of Tewarson [4] was focused on a steady-state heat balance at the fuel surface with a radiation adjustment through the Spalding number. The work of Orloff [5] illustrated the application of Froude modelling to the development of a homogeneous fire radiation correlation. As a reference fuel material used in a cone calorimeter, only solid acrylic PMMA polymer has been widely used for assessing polymer flammability and characterizing the mass loss rate during combustion processes $[8,9]$. For a heavily sooting flame such as fire, radiation is a crucial aspect of combustion, and can dominate other modes of heat transfer. No predictive burning rate simulation in a large-scale condensed pool fire in crossflow have been reported yet due to the difficulties in the prediction of the radiative flux associated with the soot formation. The effects of wind on a pool fire in crossflow are complex. Depending on the wind speed, there may be an effect of convective enhancement. Interaction between a flame and a cross-flow was described by Lavid, et al. [10] in terms of the ratio between buoyant and inertia forces in assessing if the flame is controlled by a natural or forced convection. Putman [11] investigated the behaviour of small fires, indicating that an increase of the longitudinal ventilation rate enhanced the flame length. From tests of full-scale wind aided fires [12], reduction in the flame length with an increase of wind speed was found. Whilst there has been research carried out over the years into the atmospheres associated with aircraft fires. Tests were conducted by Keltner [13] to simulate spilled fuel fires that might occur under the wing of a transport aircraft. The tests in general have been rather limited in terms of the fire-model used. A considerable effort has been made by Greiner [14] and Suo-Anttila [15] in conducting full-scale numerical and experimental simulations of the fuel evaporation rate and heat flux distributions with the presence of an object engulfed in a large fuel fire. The wind brings about improved mixing and more efficient combustion which tends to increase the flame temperature [15]. This has led to the readacross of such results from rather specific test scenarios to general aircraft fire accidents.

There is again a lack of information concerning the atmospheres generated in differing types of fire, covering a wide cross-section of situations. The occurrence of large fires which engulf an aircraft is numerically studied to simulate spilled fuel fires adjacent to the engine below the wing of aircraft. This work proposes a tractable theoretical formulation to predict the rate of vaporization of a pool fire in crossflow, based on an energy balance at the condensed fuel surface controlled by fire scenario. The developed framework considers only the phenomena essential for obtaining sufficiently accurate predictions of chemical species and thermal/dynamic fields in non-premixed turbulent flames for several engineering calculations. This makes CFD (Computational Fluid Dynamics) calculations of flame radiation in non-premixed flames of an arbitrary hydrocarbon fuel feasible, thereby making it an especially useful tool for the fire safety.

\section{Physical Modelling}

Advanced fire physics model, which is the subject of the current work, requires state-of-the-art submodels (combustion, multidimensional participating radiation, soot formation, heat transfer, etc) which are coupled with condensed fuel vaporization.

\section{Reacting system in gas phase}

Globally, the basis of the analysis is the conservation equations of mass, momentum, energy and species, a set of three-dimensional elliptic, time-dependent Navier-Stokes equations. The gas temperature in reacting 
system is derived from the energy equation including the heat release rate, which is determined from the consumption rate of the two combustibles of $\mathrm{CO}$ and fuel. The combustion processes are governed by the convection-diffusion equations for the mass fraction of fuel, $\mathrm{O}_{2}$, $\mathrm{CO}, \mathrm{CO}_{2}, \mathrm{H}_{2} \mathrm{O}$ and $\mathrm{N}_{2}$ via two chemical reaction steps. The Eddy Dissipation Concept (EDC) [16] assumes that the chemical reaction in a turbulent flow takes place where reactants and hot products are molecularly mixed. A detailed description can be found in FDS (Fire Dynamics Simulator) user guide [17].

In the version 5 or 6 of FDS, the soot yield value, defined as the fraction of the fuel mass that is converted into soot, should be specified. This empirical parameter is well known for well-ventilated fires (for example, 0.042 for kerosene and 0.037 for heptane), but cannot be applied to large-scale fires due to an increase of local equivalence ratio beyond one in under-ventilated condition. The pyrolysis rate of the condensed fuel is strongly dependent on the heat feedback from the flame associated with soot formation via radiation. Soot production in fire plumes is a highly complex subject due to the spatially-varying formation and oxidation processes, the influence of turbulent fluctuations and strong temperature, and fuel dependent effects. In order to properly calculate soot production relating to material properties, a classic principle of smoke point [18] was implanted in FDS5 which will be used in this study. Currently, we lack the ability to introduce this soot model in FDS6 due to the increasing complexity in its structure.

\section{Phase coupling conditions}

The pyrolysis model of the composite material needs effective material properties for properly estimating the thermal degradation of solid fuels in a fire situation, including evaporation, charring and internal heating. Advanced measurements on temperature-dependent, composite material property information on thermal conductivity, density, heat capacity, heat of pyrolysis and reactions Arrhenius parameters would require an extensive experimental effort. Furthermore, each material component in the composite fuel may undergo several competing reactions, and each of these reactions may produce some other solid component (residue) and gaseous species. More comprehensive and complex models would be prohibitive in the framework of large CFD problems. According to the experimental observation [19], a pyrolysis process of the charring materials gives rise to a charred surface layer and its thickness increases with time. The charred surface layer shields the heat flux and thereby limits the rate of fuel gas production. However, the presence of a forced crossflow over the composite surface facilitates crack of the charred layer. In the current model, the pyrolysis process is assumed to occur solely over the composite material surface. This simplicity allows to using a thermal equilibrium over the surface of the virgin condensed material, and the pyrolysis rate is calculated [20] with the mass balance across the interface:

$$
\dot{m}_{s}=\left(h_{m, \text { conv }}+h_{m, \text { ray }}\right) \ln (B+1)
$$

Here $h_{m, \text { conv }} / h_{m \text {, ray }}$ are the convective/ radiative mass transfer coefficients and B the mass transfer number.

The parameter $\mathrm{h}_{\mathrm{m} \text {,conv }}$ is defined as,

$$
\mathrm{h}_{\mathrm{m}, \mathrm{conv}}=\frac{\rho \alpha}{1} \mathrm{Nu}
$$

where $\rho$ is the density, $\alpha$ the thermal diffusivity, and 1 the local length scale. The Nusselt number is calculated from the Reynolds $(\mathrm{Re})$ and Prandtl $(\mathrm{Pr}=0.7)$ numbers as below :

$$
\mathrm{Nu}=m \operatorname{Pr}^{1 / 3} \operatorname{Re}^{\mathrm{n}} \text { and } \mathrm{Re}=\frac{\rho \mathrm{ul}}{\mu}
$$

The empirical constants are given as $\mathrm{m}=0.037$ and $\mathrm{n}$ $=4 / 5$ for the Reynolds number beyond $3 \times 10^{5}$, and $\mathrm{m}=$ 0.664 and $n=1 / 2$ for Re below that value.

The radiative mass transfer coefficient, $\mathrm{h}_{\mathrm{m} \text {, ray, }}$ is expressed as,

$$
\mathrm{h}_{\mathrm{m}, \mathrm{ray}}=\frac{\dot{\mathrm{q}}_{\mathrm{rad}}^{\prime \prime}}{\mathrm{C}_{\mathrm{p}}\left(\mathrm{T}_{\mathrm{g}}-\mathrm{T}_{\mathrm{s}}\right)}
$$

Here, $\mathrm{C}_{\mathrm{p}}$ denotes the gas specific heat, $\mathrm{T}_{\mathrm{s}}$ the surface temperature of the condensed fuel, and $\mathrm{T}_{\mathrm{g}}$ the gas temperature. The radiation heat flux is obtained from the radiant intensity [17], I, by solving a radiative transfer equation associated with a mean absorption coefficient in a gray medium. For situations where the condensed fuel is a diffusively reflecting and emitting surface, the radiant intensity over the burning surface is calculated by using the following expression [17],

$$
\mathrm{I}\left(\mathrm{r}_{\mathrm{s}}, \Omega\right)=\frac{\varepsilon_{\mathrm{s}} \sigma \mathrm{T}_{\mathrm{s}}^{4}}{\pi}+\frac{1-\varepsilon_{\mathrm{s}}}{\pi} \int_{\mathrm{n} . \Omega} \ln . \Omega^{\prime} \mathrm{I}\left(\mathrm{r}_{\mathrm{s}}, \Omega^{\prime}\right) \mathrm{d} \Omega^{\prime}
$$

Here, $\varepsilon$ s denotes the surface emissivity, $\Omega$ the solid angle and $r_{s}$ the direction vector of the intensity. For simplicity, six bands are selected to give an accurate representation of the most important radiation bands of $\mathrm{CO}_{2}$ and $\mathrm{H}_{2} \mathrm{O}$. For the calculation of the gray or bandmean gas absorption coefficient, a narrow-band model (RadCal) has been implemented in FDS [17]. The effect of soot concentration on radiation is included by adding the radiation coefficient of soot into that of gas.

For the solid fuel as composite material, the mass transfer number, B, is defined from the heat of combustion [20]. 


$$
\mathrm{B}=\frac{\mathrm{H}_{\mathrm{c}}{\nu_{\mathrm{F}} / \mathrm{o}}_{\mathrm{O} 2}+\mathrm{C}_{\mathrm{p}}\left(\mathrm{T}_{\mathrm{g}}-\mathrm{T}_{\mathrm{s}}\right)}{\mathrm{L}_{\mathrm{v}}+\mathrm{C}_{\mathrm{pl}}\left(\mathrm{T}_{\mathrm{s}}-\mathrm{T}_{0}\right)}
$$

Here $V_{\mathrm{F} / \mathrm{O}}$ is the stoichiometric fuel/oxygen ratio, $\mathrm{H}_{\mathrm{c}}$ the heat of combustion, $\mathrm{C}_{\mathrm{pl}}$ the liquid specific heat, $\mathrm{L}_{\mathrm{v}}$ the fuel latent heat, and $\mathrm{Yoz}_{0}$ the local oxygen mass fraction. The B-number approach as Eq.(6) is employed because its robustness and efficiency has been tested [20].

For the liquid fuel as kerosene, the mass transfer number, $\mathrm{B}$, is defined from the mass fraction of liquid equilibrium vapour, $\mathrm{Y}_{\mathrm{F}, \mathrm{s}}$, which is obtained from Clausius-Clapeyron equation [17].

$$
\mathrm{B}=\frac{\mathrm{Y}_{\mathrm{F}}-\mathrm{Y}_{\mathrm{F}, \mathrm{s}}}{\mathrm{Y}_{\mathrm{F}, \mathrm{s}}-1}
$$

Here $Y_{F}$ is the gas fuel mass fraction. Once ignition occurs over the liquid surface when the mixing between the fuel vapour and air is close to the stoichiometric condition, the Eq.(6) is also used for determining the mass transfer number.

Even with the B-number approach, the number of properties needed is staggering and we lack the ability to accurately quantify here through bench-scale experiments. Table 1 presents the temperature-independent material property found in literature [20] for the liquid fuel (kerosene), and directly measured in our laboratory for the composite material.

The condensed fuel is assumed to be thermally-thick, a one-dimensional heat conduction equation for the ma- terial temperature is solved. The surface temperature, $\mathrm{T}_{s}$, is affected by gains and losses with the heat balance across the interface:

$$
-\mathrm{k}_{1} \frac{\mathrm{d}_{\mathrm{s}}}{\mathrm{dn}}=\dot{\mathrm{q}}_{\mathrm{conv}}^{\prime \prime}+\dot{\mathrm{q}}_{\mathrm{rad}}^{\prime \prime}-\dot{\mathrm{m}}_{\mathrm{s}} \mathrm{L}_{\mathrm{v}}
$$

Here, $\mathrm{k}_{1}$ is the thermal conductivity of condensed fuel.

\section{Boundary Conditions}

Upon encountering the perturbation induced by an aircraft in crosswind, the boundary layer probably changes rapidly from transition into a fully turbulent one. The viscous sublayer is critically dependent on the near-wall model due to important viscous effects. An extremely small grid size $(\mathrm{mm})$ is required to fully resolve the turbulent boundary layer and the complex flow instabilities in the wake behind the cylinder for the high Reynolds number flow, making practical fire simulations difficult. In the present work, the computational nodes immediately adjacent to a solid wall are located in the fully turbulent region. The Couette flow is assumed to prevail near the wall surface, and the convective heat feedback is calculated from a wall function [21] far away from the wall for viscous effects to be negligible.

$$
\dot{\mathrm{q}}_{\text {conv }}=\frac{\left(\mathrm{T}_{\mathrm{g}}-\mathrm{T}_{\mathrm{s}}\right) \rho \mathrm{C}_{\mathrm{p}} \mathrm{C}_{\mu}^{1 / 4} \mathrm{k}^{1 / 2}}{\operatorname{Pr}\left[\frac{1}{\kappa} \ln \left(\mathrm{Ey}^{+}\right)+\mathrm{P}\right]}
$$

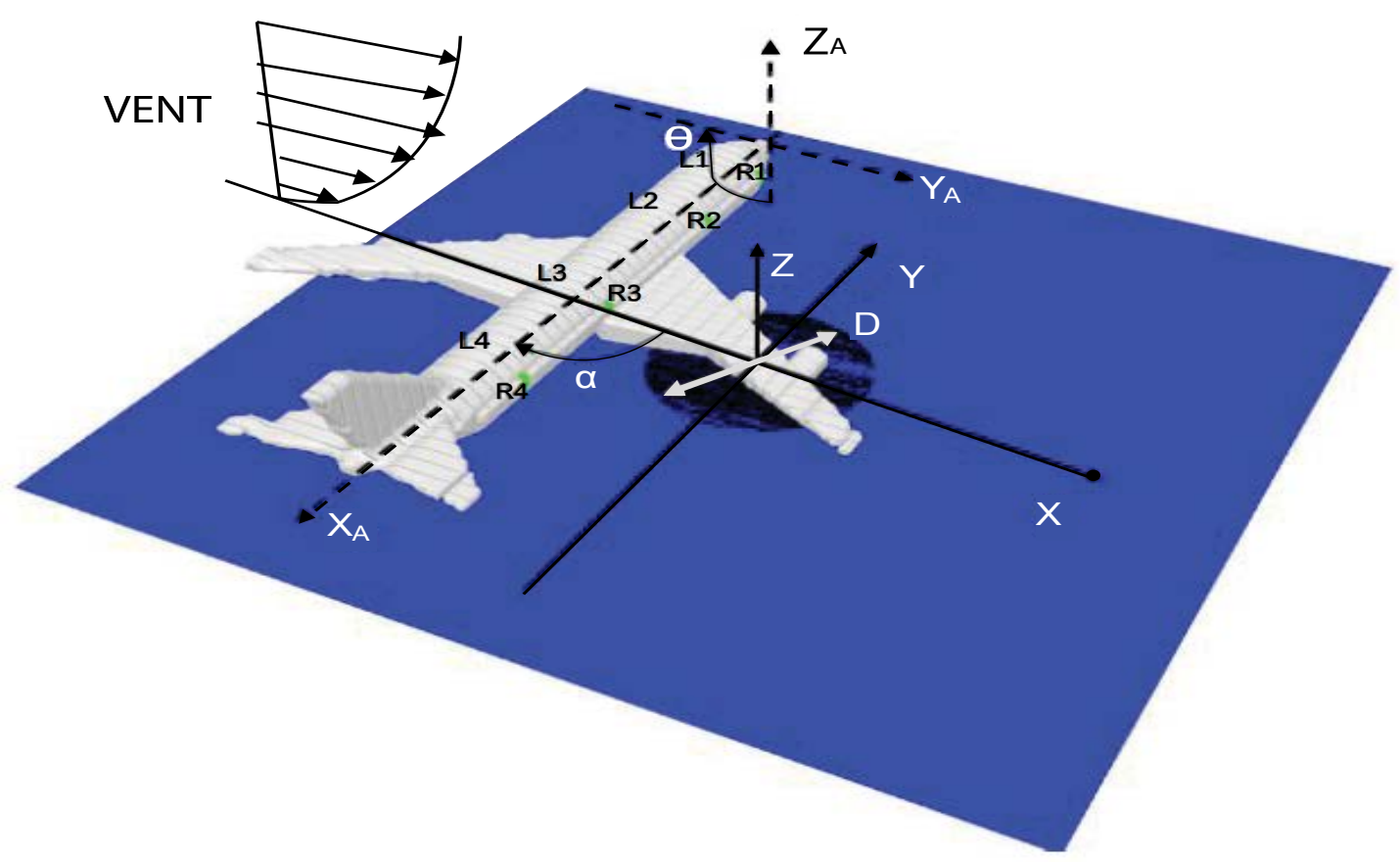

Figure 1: Schematic diagram of the aircraft engulfed in a large pool fire subjected to a wind and coordinate system in the numerical simulation. 
Here $C_{\mu}$ and $\mathrm{E}$ are the constants in logarithmic law of the wall, $\kappa$ is the von Karman constant, Pr the Prandtl number, $\mathrm{k}$ the turbulent kinetic energy, $\mathrm{y}^{+}$the nondimensional distance from the wall and $\mathrm{P}$ an empirical function defined by Djilali [21]. This simplicity allows faster computations and by this a higher spatial discretization and an increase of the resolved part of the fire oscillation. Besides, predictions of the most dominant radiative heat transfer are generally less sensitive to the near-wall turbulence model. The cylindrical fuselage is approximated by using small steps of $0.15 \mathrm{~m}$ in height. The velocity profile of the incoming or free-stream flow, which is assumed turbulent, is assigned a logarithmic one appertaining to fully-rough flow [22]. The free-stream flow conditions are imposed to the other boundaries.

\section{Computational domain and mesh size}

Given in Figure 1 is a schematic diagram of the aircraft engulfed in a large pool fire subjected to a wind and coordinate systems in the numerical simulation. The symbols $\mathrm{L}$ and $\mathrm{R}$ denote the left and right door slides. The coordinate system $\left(\mathrm{X}_{\mathrm{A}}, \mathrm{Y}_{\mathrm{A}}, \mathrm{Z}_{\mathrm{A}}\right)$ is fixed at the head of the aircraft for the analysis of the incident heat flux on the skin of the aircraft fuselage, and the one $(\mathrm{X}, \mathrm{Y}, \mathrm{Z})$ for the temperature, velocity, chemical species, etc. in gas phase. The calculations were performed using a computational mesh, which was made up of $200 \times 200 \times 250$ cells with overall dimension of $90 \mathrm{~m}$ in length (x), $90 \mathrm{~m}$ in width $(\mathrm{y})$ and $100 \mathrm{~m}$ in height $(\mathrm{z})$.

For the aircraft fire considered, the lowest peak value in HRR is about $400 \mathrm{MW}$, giving a characteristic length [16] of about $18 \mathrm{~m}$. The gross features of the fire plume phenomena can be correctly described when the characteristic length is spanned by roughly sixteen computational cells, giving a grid size of about $1 \mathrm{~m}$. The grid is locally refined with extra grid points being added in strong shear stress zones, such as near the pool fire surface, around the cylindrical fuselage, and in the wake region behind the aircraft. Along the length, $\mathrm{x}$, cell sizes start at $0.15 \mathrm{~m}$ around the pool fire, and stretch to about $1 \mathrm{~m}$ at the free boundary. In the $\mathrm{z}$ direction, cell sizes are approximately $0.1 \mathrm{~m}$ in the vicinity of the burning zone and stretch to about $1.2 \mathrm{~m}$ near the free boundary. A uniform grid is used with a cell size of approximately $0.45 \mathrm{~m}$ in the transversal direction, y. Comparison indicates some minor changes, but the basic characteristics of the flow are unaltered when the resolved length scale in LES, is of the order of $0.2 \mathrm{~m}$ in the reactive zone. This simplicity allows faster computations and still permits a high spatial discretization and an increase of the resolved part of the fire oscillation. In fact, upon encountering the perturbation of the fire plume near the ceiling, an extremely small grid size $(\mathrm{mm})$ is required to fully resolve the stratified layer flow recirculation and the complex flow instabilities around aircraft, making practical aircraft fire simulations difficult. Thus, the greatest source of error in the numerical simulation may originate from the sub-grid viscosity and the numerical diffusion both depending on the mesh size. The simulated physical time is about $180 \mathrm{~s}$ in transient mode with a time-step of about $10^{-4} \mathrm{~s}$, and CPU time was of the order of two or three weeks as a function of the wind condition. The baseline grid simulations use 16 processors through parallel processing of a Linux cluster. Up to now, investigations of the large-scale fire are limited to computations on relatively coarse meshes everywhere [22].

\section{Results and Discussion}

It is relatively easy task of obtaining experimental data available in intermediate-scale pool-like fires for a detailed comparison between prediction and experiment. In our previous studies [23,24], several intermediate- or full-scale pool-like fires have been taken, expressly to test the robustness and efficiency of the numerical model. Globally, the numerical model is capable of reproducing the temperature and velocity profiles, the magnitudes of $\mathrm{CO} /$ soot and distribution of the heat flux. The experimental data from large-scale aviation liquid pool fire with presence of an aircraft are not available. In the current study, the official investigation report [25] for the acci-

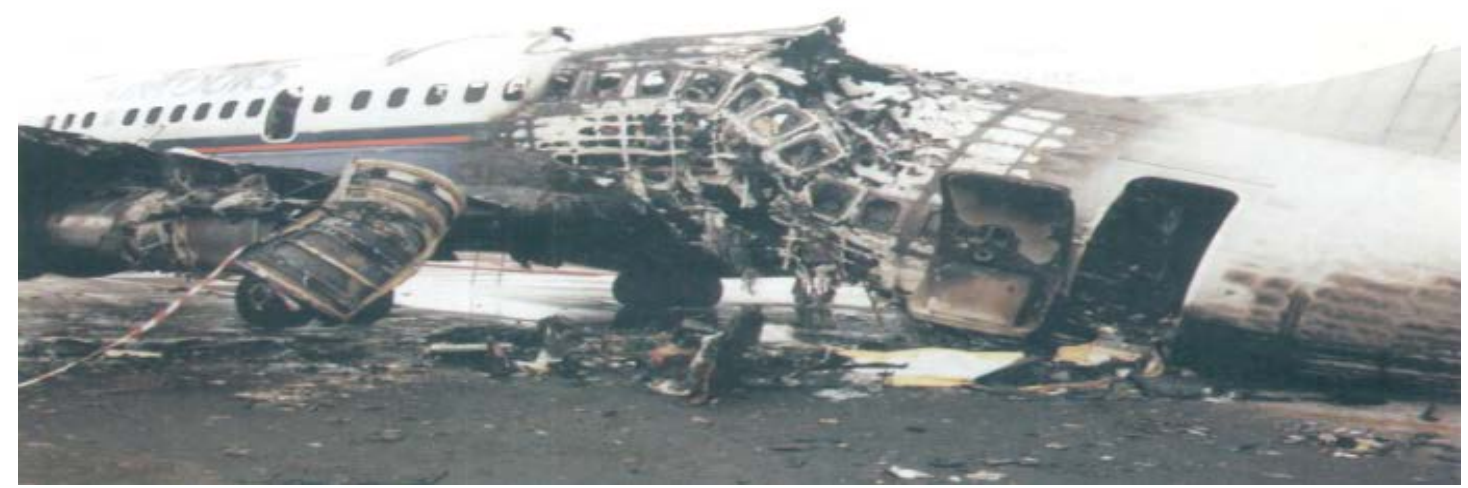

Figure 2: View from a video camera [25] of the accident of B737-236 due to engine failure at Manchester airport in 1985. 
dent of the aircraft B737-236 at Manchester is used for evaluating the feasibility for simulations of a full scale aircraft immersed within a large aviation-fuel fire. Then, according to the European Project, this study is intended to simulate a pooled-fuel ground fire attack on the fuselage skin for B747 or A350 family and a door aperture representing a breach in the fuselage of as a function of the wind speed and direction.

\section{Evaluation of the numerical model from a post- crash fire of the aircraft B737}

The accident of the aircraft B737-236 at Manchester airport in 1985, as shown in Figure 2 from a video camera [25], was mainly due to engine failure. It was found that some turbine blade rubbing had occurred apparently due to engine case distortion. Fuel released from the wing tank puncture fell mainly as a column of liquid, hitting the ground where it broke up into a coarse spray. Although there is no direct evidence of when the fire started, there can be little doubt that it ignited immediately as fuel released from the punctured wing came into contact with hot material and combustion flames escaping from the left damaged engine. Efficient mixing of the fuel and air occurred, resulting in a hot, stable flame which burned within, and was controlled by the turbulent wake boundary. As the aircraft decelerated, the turbulent wake which entrained much of the fuel and sustained the dynamic fire plume decayed, and the fire transitioned into a quasi-static fire burning above the increasingly large pool of fuel trailing behind the aircraft. The pooled fuel fire results in a large and intense fire outside the hull, falls into two subcategories: those where the fuselage has been ruptured to some degree, as result of crash damage for example, giving the fire direct access to the cabin interior; and those in which the hull is initially intact and capable of presenting a barrier to the external fire as was the case at Manchester [25]. Penetration of fuselage side by external static main fire plume after aircraft had stopped, induced 55 fatalities among 135 passengers. A schematic diagram of this post-crash fire engulfing the aircraft B737-236 with a length of about $30 \mathrm{~m}$ is shown in Figure 3. The coordinate system $(\mathrm{X}, \mathrm{Y}, \mathrm{Z})$ is fixed at the pool fire center on the left side of the aircraft for approaching the accident situation, and the coordinate system $\left(\mathrm{X}_{\mathrm{A}}, \mathrm{Y}_{\mathrm{A}}\right.$, $\mathrm{Z}_{\mathrm{A}}$ ) is unchanged.

The official investigation report [25] emphasizes the dominant role of the component of the wind velocity parallel to the aircraft moving direction on the distribution of temperature and chemical species outside of the cabin. The relative wind changed from a slight crosswind component from the right to a larger crosswind component from the left, placing the cabin downwind of the fire. As shown in Figure 3, the dominant wind direction relative to the axis of the aircraft is characterized by an angle $\alpha=70^{\circ}$ and the average wind speed is about 3.5 $\mathrm{m} / \mathrm{s}$. After aircraft had stopped, the fire transitioned into a quasi-static fire burning, and the liquid fuel was estimated to burn in a circular sheet of approximately

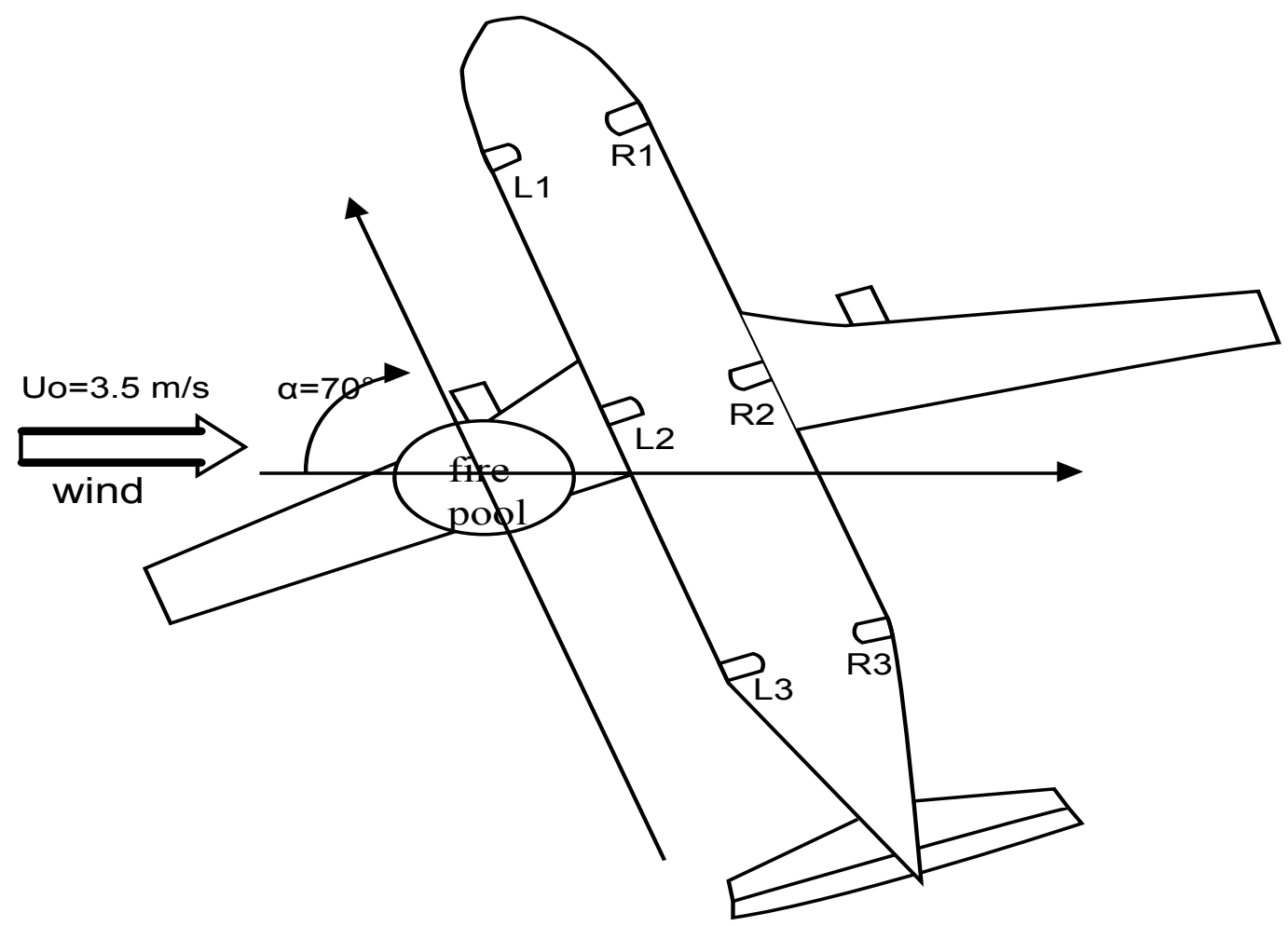

Figure 3: Schematic diagram of the post-crash fire engulfing the aircraft B737-236 subjected to a wind. 


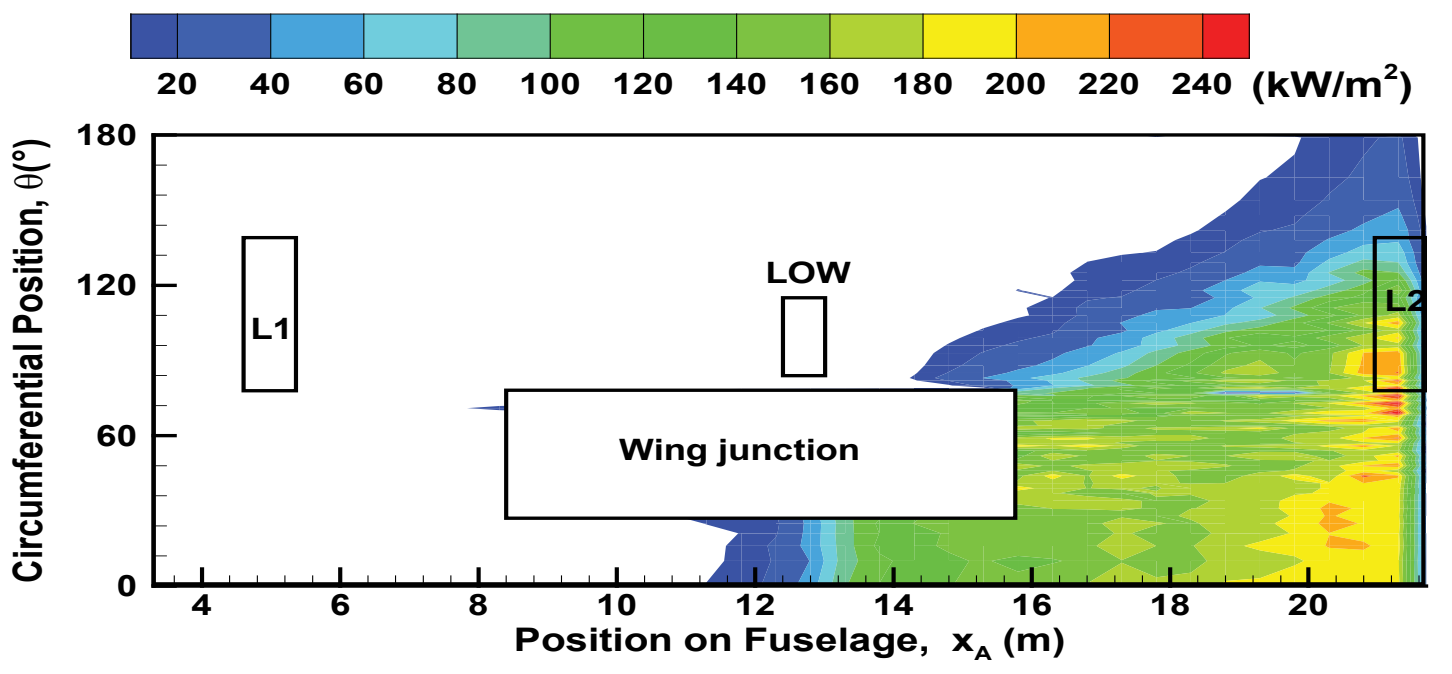

Figure 4: Iso-contour of the incident heat flux on the skin of the aircraft fuselage during the post-crash fire.

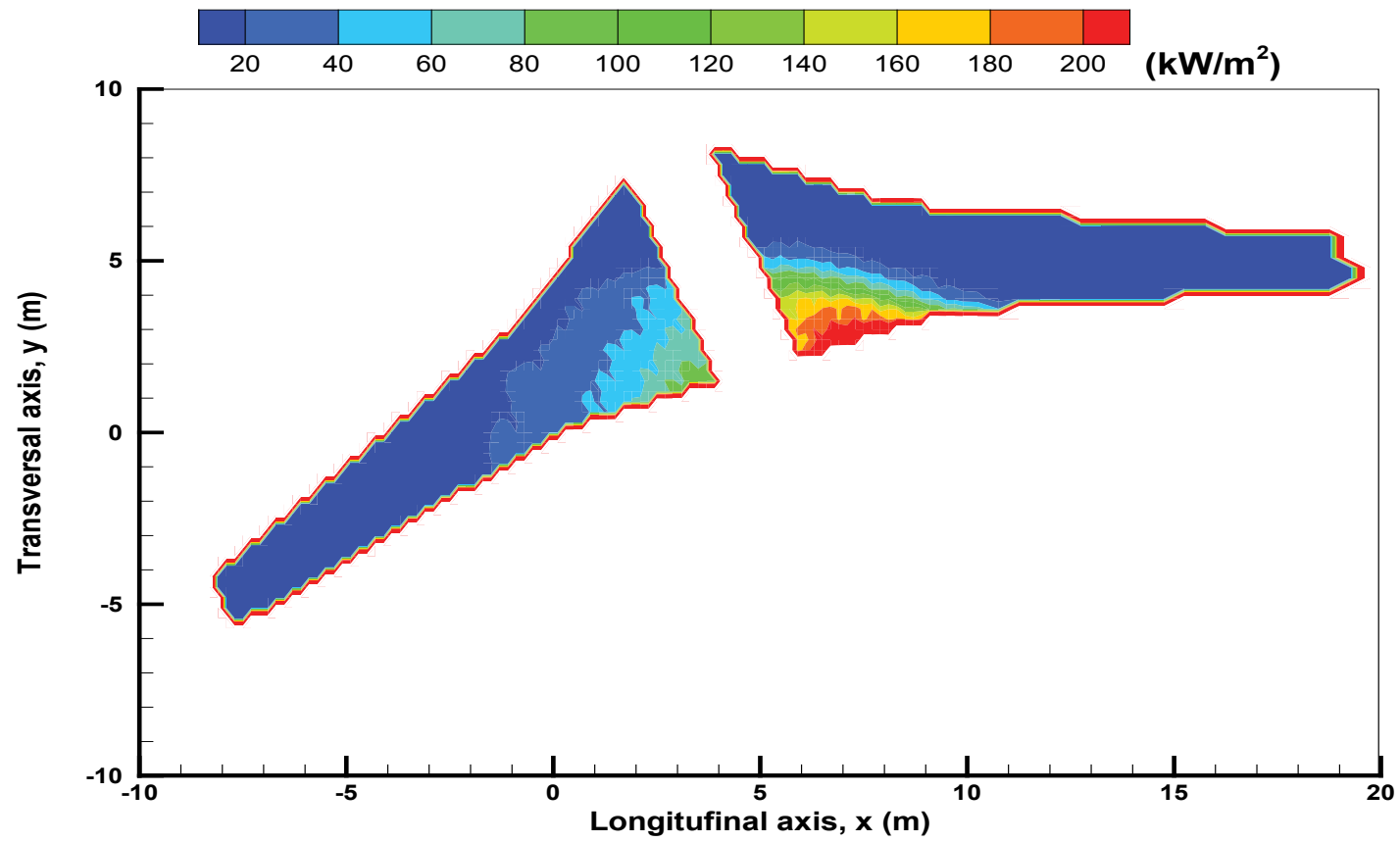

Figure 5: Iso-contour of the incident heat flux on the skin of the aircraft wings during the post-crash fire.

$10 \mathrm{~m}$ in diameter. A tray of kerosene with an area of about $78 \mathrm{~m}^{2}$ was ignited immediately outside the cabin and the resultant thermal radiation initiated an internal fire amongst the cabin furnishings. The unknown key parameter, such as the Heat Release Rate (HRR) of the external fire, is predicted from CFD simulation with an approximate value of $400 \mathrm{MW}$. The key known outcomes of the fire and evacuation analysis is taken here for comparison with the numerical results.

Influence of the aircraft position in the wind-translated flame on the heat flux distribution over the fuselage skin is evidenced in Figure 4. The peak in heat flux at the right end of the aircraft is up to $200 \mathrm{~kW} / \mathrm{m}^{2}$, which in general is greater than this at the left end. This is a result of the redirection of the flame zone towards the tail of the aircraft by the component of the wind velocity parallel to the aircraft moving direction. Because the heat flux is flame dominated, it drops when the flame is absent at the left end of the aircraft. As illustrated in Figure 5, the heat flux over the right wing skin in the vicinity of the fuselage is up to $240 \mathrm{~kW} / \mathrm{m}^{2}$, which is higher than the one over the left wing skin. The heat flux on the wing skin is an increasing function of the intensification of the turbulent flame on the fuel-rich region. Because this fire emerged on the forward of the right wing, the stronger heat flux on the right side is partly as a secondary plume of fire clinging to the fuselage skin, and partly as a more billowing fire burning inside the region of turbulence beneath fuselage. Within this region of turbulence, the fire is in- 
tensified on the right wing side by a mixing of partially burnt fuel residues with air, and its damage potential increases still further by the presence of large volumes of soot particles, which enhances the fire's radiative efficiency. Generally, the strong heating under a heat flux of $100 \mathrm{~kW} / \mathrm{m}^{2}$ reflected the degree of fire damage evident in the adjoining area of cabin (cf. Figure 2). The wing skin and access panel were not designed to any impact criteria and nor where they required to be.

The aircraft was equipped with four main cabin doors (L1, L3, R1, R3), and two overwing emergency exits (L2, R2) as shown in Figure 3. Iso-contours of the predicted temperature at the exit openings are shown in Figure 6. The temperature possesses large spatial fluctuations, demonstrating the effects of a buoyancy-controlled pool fire. It was observed that during the post-crash fire, a thermal layer containing hot gases and soot was carried by the forced convection towards the tail of the aircraft. Nei- ther L1 nor R1 door had suffered significant damage during the fire. Some passengers exited via the front (L1, R1) and the right (R2) exits escaped before thick smoke had reached them. The opening time for evacuation was about $25 \mathrm{~s}$ at the left exit L1, $70 \mathrm{~s}$ at the right exit R1, and $45 \mathrm{~s}$ at the right over-wing R2 door. From the numerical simulation, the levels of the temperature are tenable at these exit openings (L1, R1, R2) for evacuation. The fire damage pattern with a temperature level beyond $500{ }^{\circ} \mathrm{C}$ in the vicinity of the L3 or R3 door aperture suggest that the door was a major point of entry for fire, although it is likely that occasional flame transients may enter the doorway. The curtain immediately inside the door would be subject to substantial radiant heat from the fire plume burning. At this point, the R3 slide temperatures soared to approximately $1200^{\circ} \mathrm{C}$, and the $\mathrm{R} 3$ door had deployed fully, but had subsequently been partially burnt in the ground fire, causing deflation.

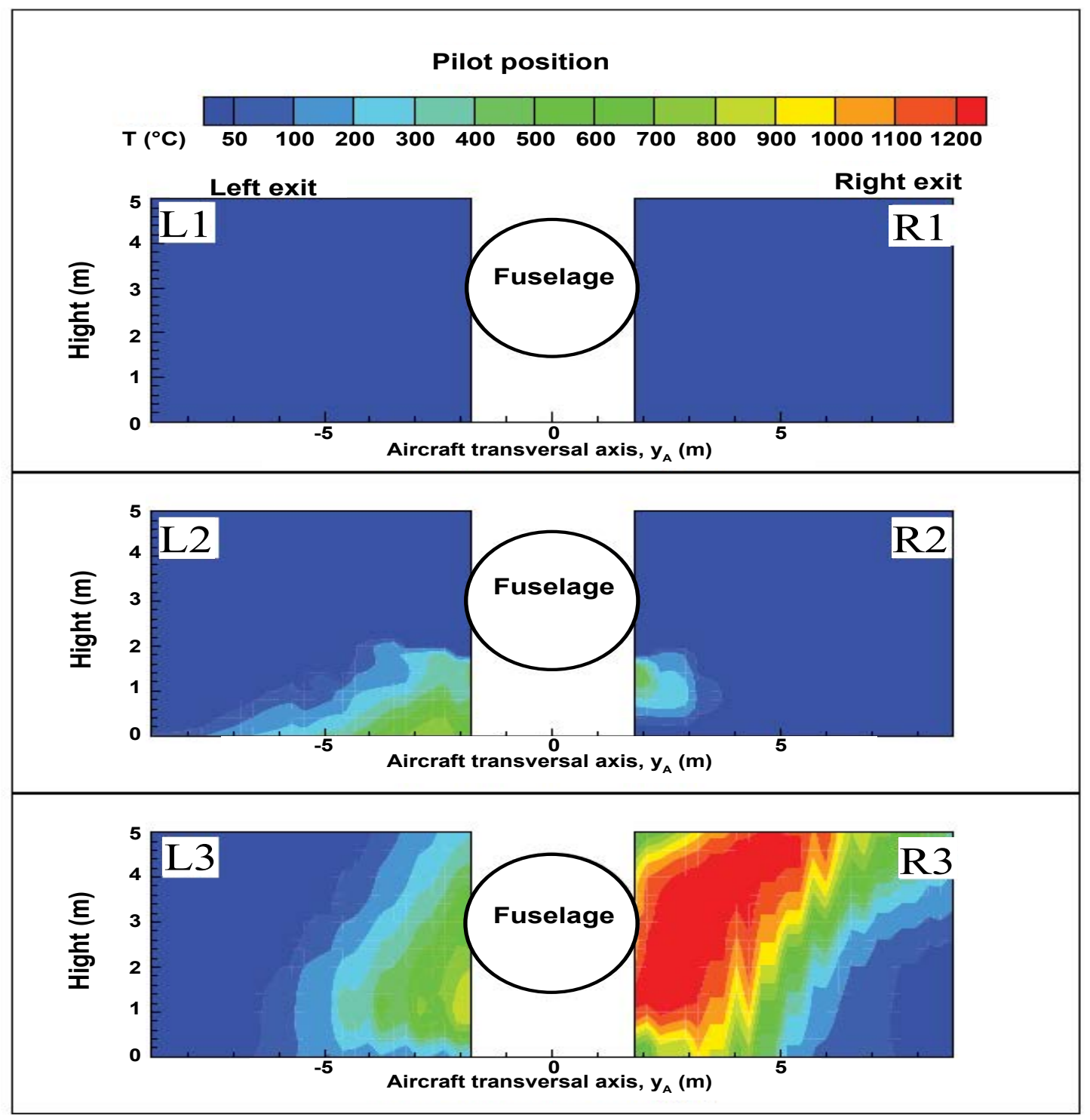

Figure 6: Iso-contours of the time averaged temperature at the left and right exit openings. 


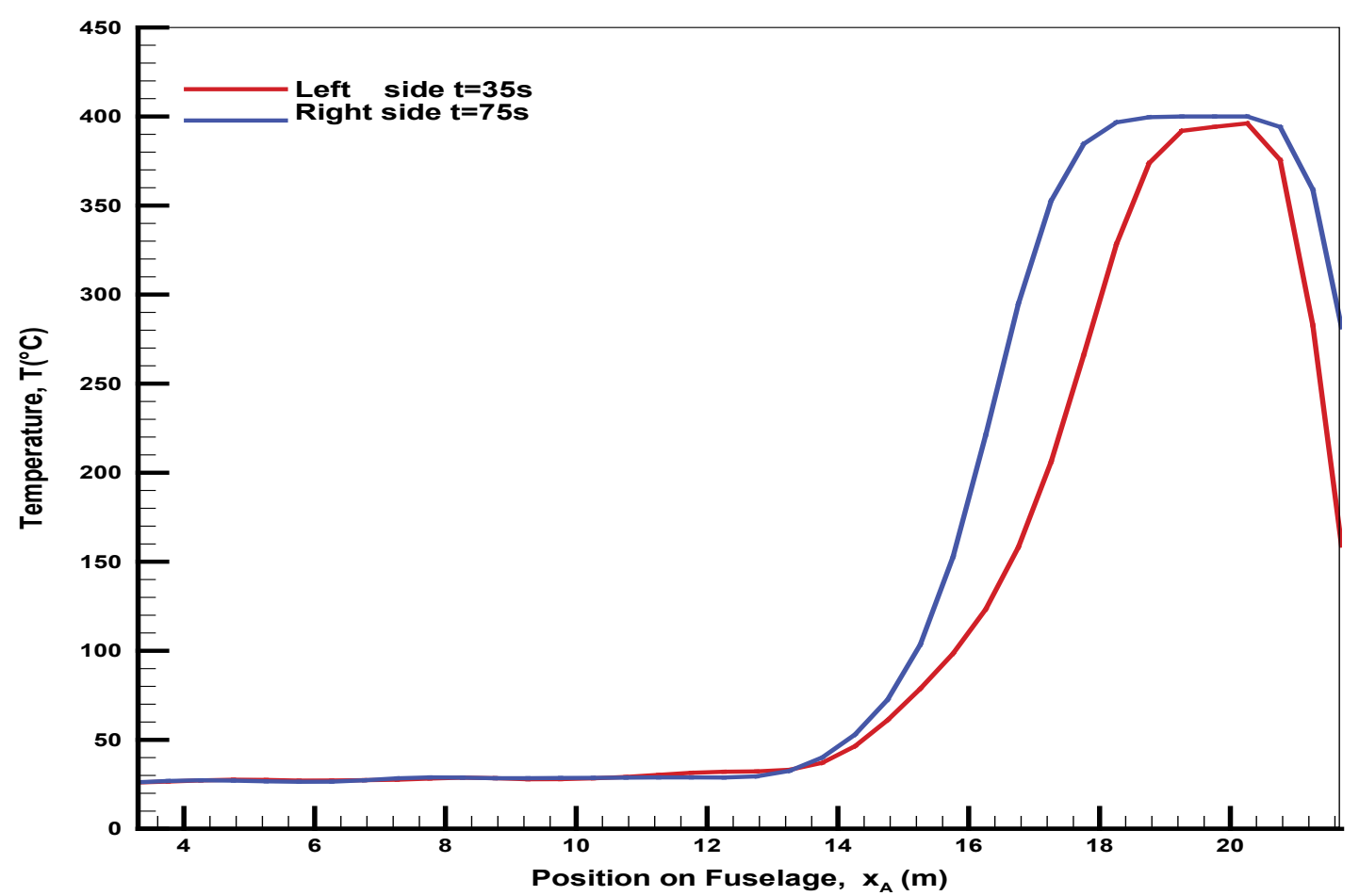

Figure 7: Evolution of the predicted temperature along the fuselage along the window locations at the melting point.

An accurate start time and duration of the fuselage burn-through are unavailable from the official investigation report [24]. Each cabin window comprised an assembly of three acrylic panels mounted into individual recessed forged aluminum frames. Acrylic is a thermoplastic material which starts to soften at temperatures of approximately $100{ }^{\circ} \mathrm{C}$ and to burn at about $400{ }^{\circ} \mathrm{C}$. Distributions of the temperature level along the window locations are presented in Figure 7 at the time of $35 \mathrm{~s}$ on the left side, and $75 \mathrm{~s}$ on the right side at the window burning point. The shorter time reaching burn-through $\left(400^{\circ}\right)$ of the plastic-type windows at the left side is mainly due to the redirection of the external flame impingement on the fuselage at the left end of aircraft by the wind component parallel to the aircraft moving direction. Examination of the window panels indicated that the following external fire penetration mechanism had occurred. The window panels melted down at a burning point of about $400{ }^{\circ} \mathrm{C}$ on the left side at $35 \mathrm{~s}$ and on the right side at $75 \mathrm{~s}$. During the post-crash fire, smoke $\left(\mathrm{CO}, \mathrm{CO}_{2}, \mathrm{H}_{2} \mathrm{O}\right.$, soot, etc.) began entering the galley area sometime after $70 \mathrm{~s}$. By taking into account the thermal barrier of the window assembly with three acrylic panels, penetration of the combustion products to the interior of the cabin occurs after $70 \mathrm{~s}$, providing the same orders of magnitude for the evacuation time. The fire damage on the doors and window apertures at the rear of the aircraft emphasizes the importance of considering the wind-induced interaction of fires and aircraft when determining the evacuation strategies. The fuselage was of conventional con- struction utilizing aluminium alloys for the main structural components and the external skin. The numerical results suggest that the aluminum alloy fuselage is gradually heated up to its melting temperature of approximately $700{ }^{\circ} \mathrm{C}$ with about one minute. Later, fuselage crown skins melted and burnt through by internal cabin fire. As the internal fire became fully established and the roof started to burn through, the influence of the wind would have diminished somewhat.

In addition it is the case, from pathological examination, that the majority (80\%) of fire fatalities occur not due to direct and excessive thermal assault, but due to smoke/gas incapacitation. Survival and escape of passengers in a transport cabin fire may be impaired or prevented by smoke and toxic gases. The wind direction relative to the aircraft moving direction affects significantly the toxic products distribution at the exit openings. Iso-contours of the predicted toxic emissions as $\mathrm{CO}$ at the exit openings are shown in Figure 8. The soot production is strongly correlated with the trend of the CO generation, and the region of $\mathrm{CO}$ in abundance is indicative of an oxygen-starved area. From the numerical simulation, the carbon monoxide concentration appears negligible (approximately $100 \mathrm{ppm}$ ) at the door slides L1 and R1, and many passengers exited via the front (L1 and R1) before flashover inside cabin. Some passengers escaped also via the right exit R2 because a high level of $\mathrm{CO}$ is localised only in a small region at the lower part of the R2 door. Abundant $\mathrm{CO}$ and soot productions are formed in the oxygen-lean fuel-rich reacting zone in the vicinity of the 


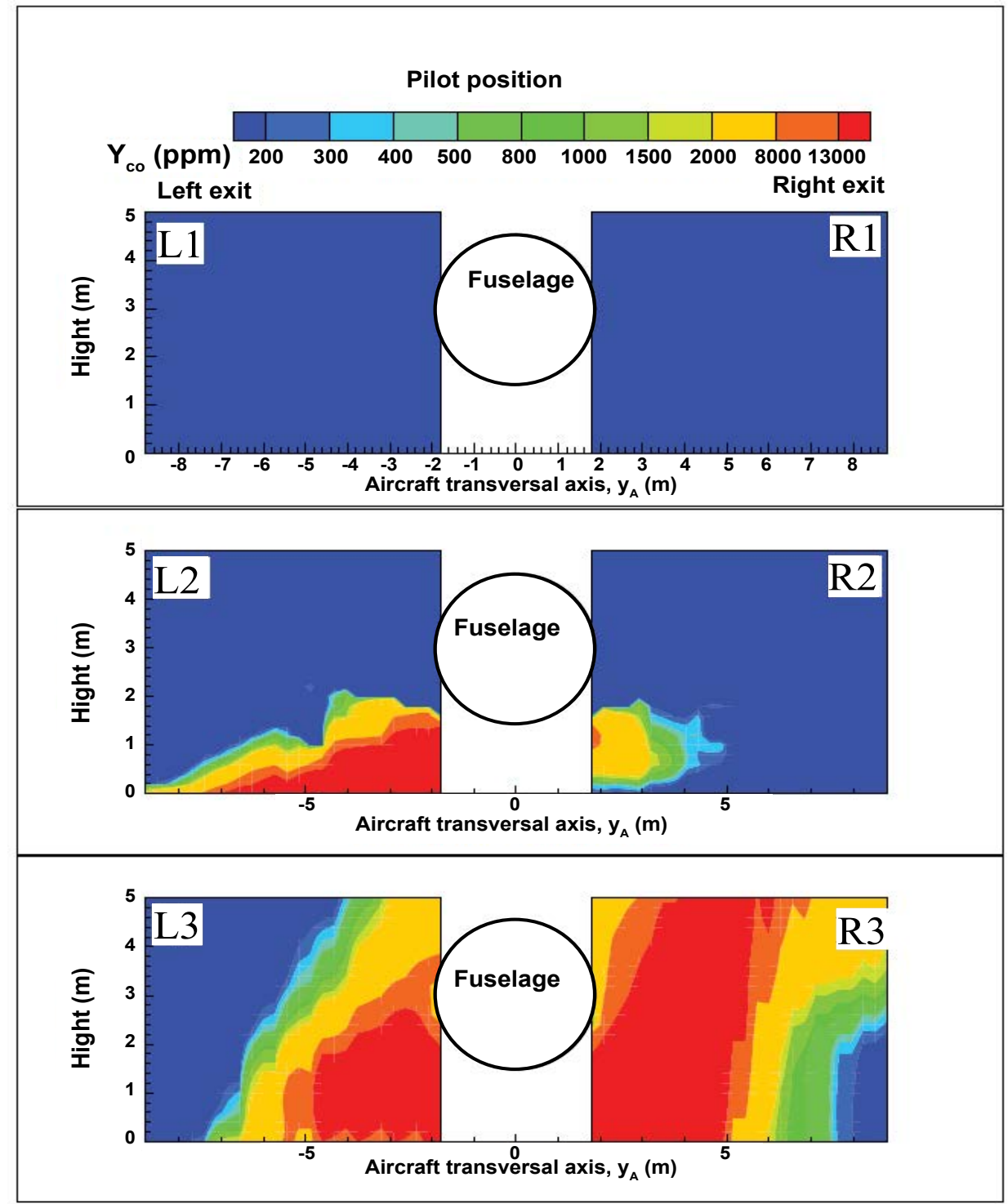

Figure 8: Iso-contours of the time averaged monoxide carbon at the exit openings.

L2, L3 and R3 doors because the flame is ejected from underneath of the aircraft, inducing a large flame base drag below the wings.

\section{Impact of the atmospheric conditions on aircraft post-crash fire}

In fact, scenarios of an aircraft post-crash fire are highly variable because of the extremely varied nature of wind conditions in an airport. In this section, the aircraft with a length of about $65 \mathrm{~m}$ and a diameter of $5.5 \mathrm{~m}$ is considered (for example, B747 or A350 family). The source of spilled fuel adjacent to the engine below the wing is about $25 \mathrm{~m}$ far from the fuselage. The aircraft is elevated at a height of about $2 \mathrm{~m}$ from the floor. The aircraft orientation relative to the external post-crash fire in crosswind, and area of the spilled fuel are the important parameters. In particular, the possibility of determining the wind condition (direction and speed) under which passenger evacuation can be performed is of great practical interest. The wind direction directly affects the apparent shape of the flame, and therefore, the temperature distribution around the aircraft. The directed flame favors an extremely rapid increase in the surface temperature of the fuselage. The atmospheric condition, characterized by fluctuations in the wind speed and direction, can't be taken into account in the current simulation. Therefore, the influence of deviation in the wind speed on the behavior of the fire is studied by taking into account a speed range of $0-10 \mathrm{~m} / \mathrm{s}$. The description of the results is also oriented on the effects of aircraft orientation relative to the wind direction on the major changes in the overall flame structure and consequently, the heat flux on the fuselage or wing skin. The wind direction relative to the aircraft moving direction is characterized by an angle $\alpha$ that varies from 0 to $360^{\circ}$, as illustrated in Figure 1 .

Burning rate of the liquid and solid composite fuels: This analyses consider a liquid pool fire burning at steady-state after the initial stages of a fire. The heat feed- 
back from the flame to the liquid pool surface affects directly the liquid heating rate to its boiling point of about 220 ${ }^{\circ} \mathrm{C}$ and consequently, its vaporization rate. History of the mass loss rate of liquid fuel for the different wind intensity is presented in Figure 9. The global regression rate is found to increase from $60 \mathrm{~g} / \mathrm{m}^{2} \mathrm{~s}$ to a value of approximately $70 \mathrm{~g} / \mathrm{m}^{2} \mathrm{~s}$ with a rise of the wind velocity to $2 \mathrm{~m} / \mathrm{s}$. A further increase of the wind speed to $5 \mathrm{~m} / \mathrm{s}$ strengths the mixing of the reactants and induces the most rapid regression of the liquid fuel as a result of the enhanced heat flux. Several studies show significant increases in the burning rates of large open-air liquid pools with increased wind [26]. The high wind speed of $10 \mathrm{~m} / \mathrm{s}$ greatly attenuates radiative feedback to the liquid fuel surface due to reduction in the flame cover, thereby depressing the fuel burning rate. Besides, the oxygen below the fuselage is particularly low due to the accumulated fuel inside the gap, resulting in a decrease of the mass transfer number B, and consequently, of the regression rate (cf. Eq.6). The mass loss rate of the liquid fuel is about $90 \mathrm{~g} / \mathrm{m}^{2} \mathrm{~s}$ for the wind speed of $5 \mathrm{~m} / \mathrm{s}$, which represents an increase of about $30 \%$ compared to that for a high speed of $10 \mathrm{~m} / \mathrm{s}$. The average fuel recession rate is about $6-7 \mathrm{~mm} / \mathrm{min}$ as a function of the wind speed, which follows closely the fuel recession rate of $6.3 \mathrm{~mm} / \mathrm{min}$ measured during the course of the experiment in a $9.1 \mathrm{~m}$ by $18.3 \mathrm{~m}$ pool [27]. Note that the mass loss rate of liquid fuel is practically insensitive to aircraft orientation relative to the wind direction.

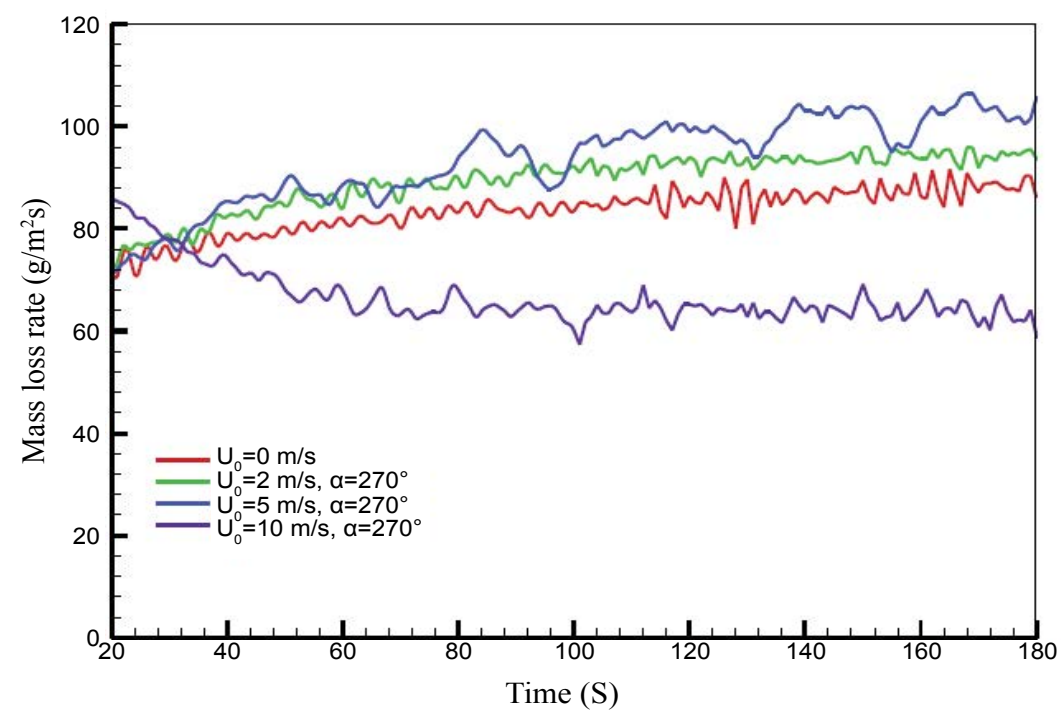

Figure 9: History of the mass loss rate of the liquid fuel during the fire propagation over the composite-type aircraft for the different wind speeds.

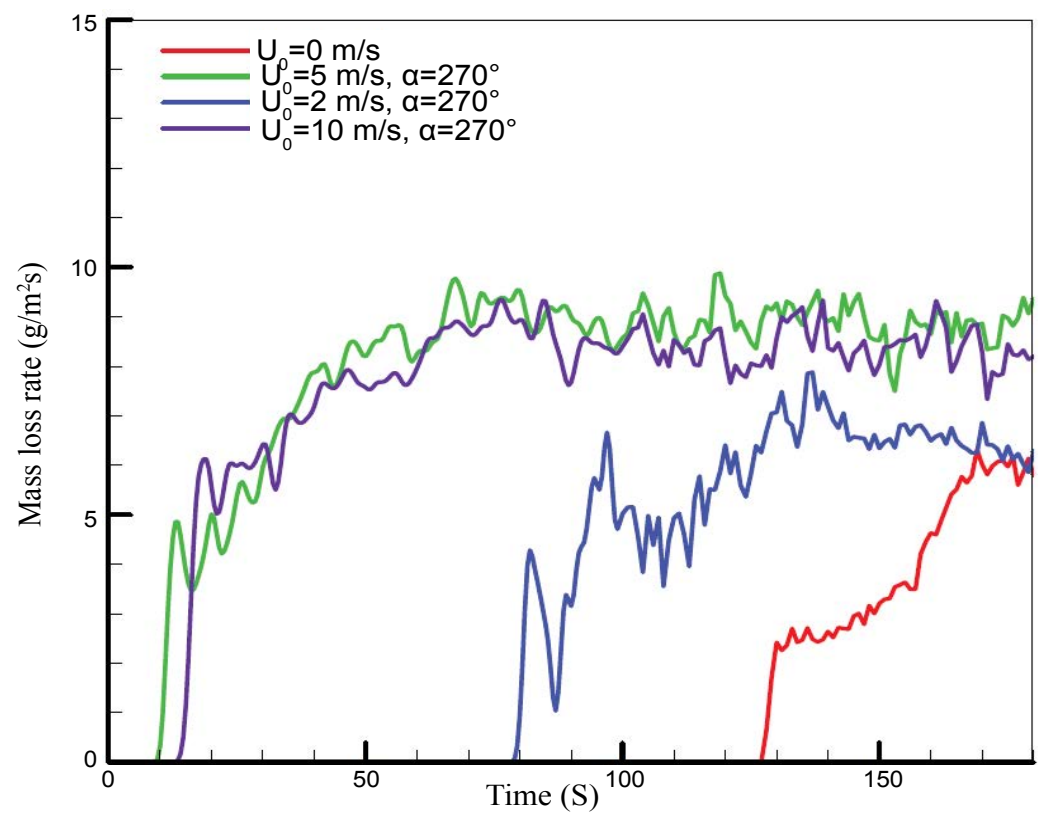

Figure 10: History of the mass loss rate of the composite material for the different wind speeds. 
History of the global mass loss rate of the composite material averaged over the total pyrolysis surface is presented in Figure 10 at various wind speeds when the aircraft moving direction is perpendicular to the crosswind. It is seen that during the flame spread period, the mass loss rate increases quickly when an actively burning region over the composite surface is present, and is generally higher at strong wind velocity. For a wind speed below $2 \mathrm{~m} / \mathrm{s}$, the flame stands up into a plume in front of aircraft under a buoyancy-controlled condition, and hence, about $80 \mathrm{~s}$ are required to starting degradation of such composite material. Increase of the wind speed strengthens significantly degradation of the composite-type fuselage due to the enhanced impact of the flame on the fuselage skin. When the ratio (Froude number) of the inertia force to the buoyancy one is great for a wind velocity beyond 5 $\mathrm{m} / \mathrm{s}$, only $10 \mathrm{~s}$ is sufficient for starting degradation of the composite material. When the flame propagation is fully developed, the heat release rate reaches its maximum value. During the steady state period, the burning rate per unit area of composite material increases with wind speed up to $2 \mathrm{~m} / \mathrm{s}$, beyond which limit it becomes largely independent of wind. This dependence is related to the burning regime which becomes increasingly dominated by radiation as soot levels rise up to a value where the fire is effectively optically thick and saturated. Note that the mass loss rate of composite material is rather sensitive to aircraft orientation relative to the wind direction due to change in the view factor from flame to the exposed fuselage skin. Globally, burning rate of the composite-type aircraft becomes the strongest when the aircraft moving direction is perpendicular to the crosswind in particular for the wind speed beyond $5 \mathrm{~m} / \mathrm{s}$.
Distribution of the thermal plume: As an illustration, the instantaneous shape of the flame where the gas temperature is higher than $500{ }^{\circ} \mathrm{C}$, from the liquid fuel in the plane perpendicular to the fuselage for two wind speeds $\left(\mathrm{U}_{0}=2\right.$ and $\left.10 \mathrm{~m} / \mathrm{s}\right)$ is given in Figure 11. Surrounding the cone of fuel vapour is a zone of luminous persistent flame. Above this zone is a further combustion region, but here there is intermittency and obvious turbulence in the flaming. Finally there is the non-reacting buoyant plume, which is generally turbulent in nature. Wake regions are formed around aircraft and at times, spiralling vortex flows are seen in the plume. For a low Froude (ratio between buoyant and inertia forces) number flame $\left(U_{0}=2 \mathrm{~m} / \mathrm{s}\right.$, Figure 11a), shear-stresses between hot combustion products and fresh air make the flow unstable and amplify oscillations near the fire base due to air entrainment variation and flame flicker, inducing large eddy structures corresponding to hot gases puffs burning. Fresh air entrained by these vortexes feeds the flame with oxygen and cools the smoke influencing natural convection and then air entrainment. In the natural convection limit, as the Froude number increases $\left(\mathrm{U}_{0}=\right.$ $10 \mathrm{~m} / \mathrm{s}$, Figure $11 \mathrm{~b}$ ), coherent structures appear also surrounding the cone of fuel vapour, the flame presenting a pronounced instability due to crossflow. There are other complications deriving from the intermittency of the behaviours, with luminous regions of efficient combustion appearing randomly in the outer surface of the fire according to the turbulent fluctuations in the fire plume. Secondary fire plume from fire entrains beneath belly of fuselage. Fire from burning fuel pool is carried by wind against, under and over the fuselage.

The time-averaged temperature field on a wind-assist-

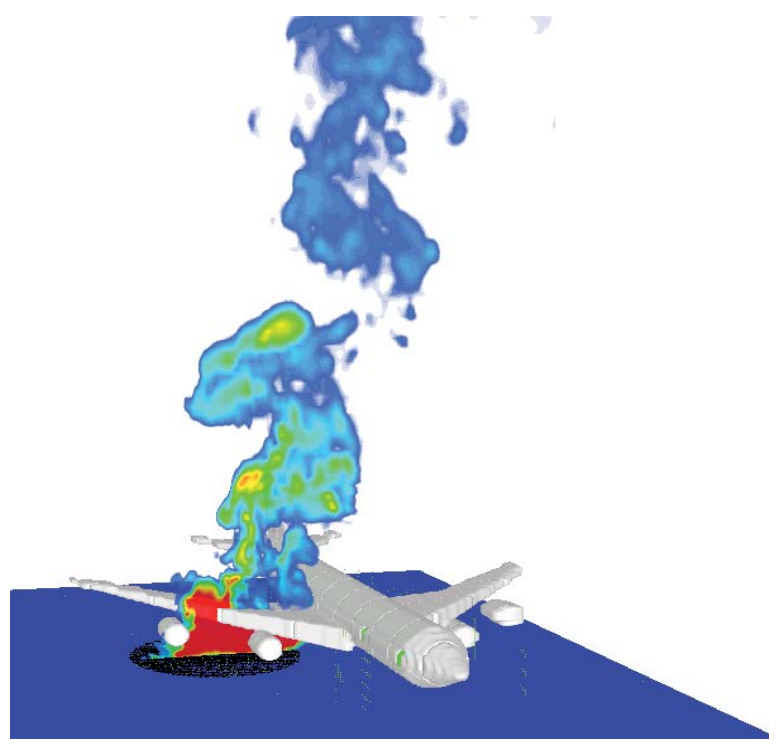

a) Low wind speed of $2 \mathrm{~m} / \mathrm{s}$
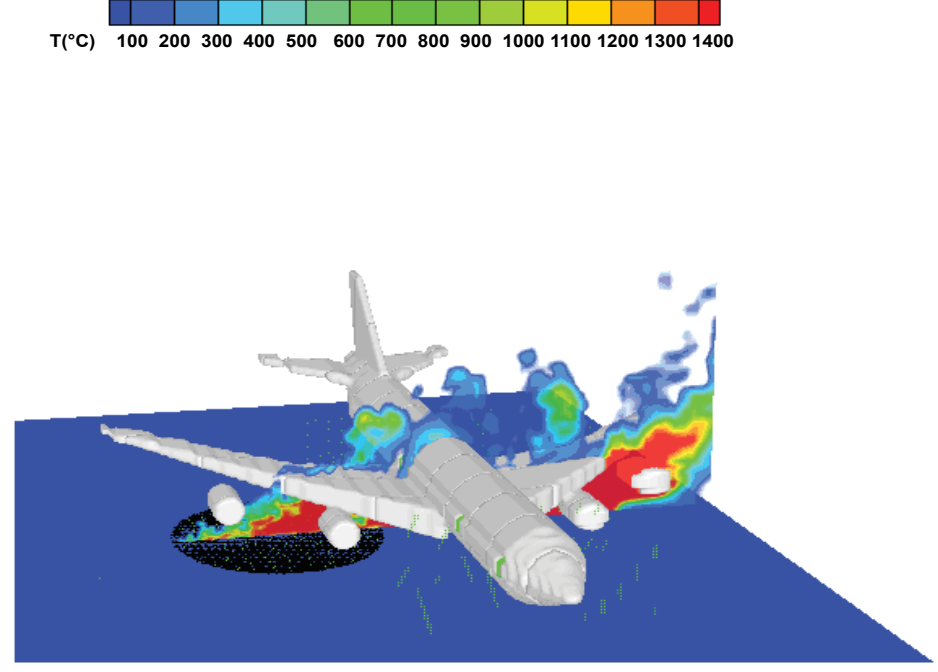

b) High wind speed of $10 \mathrm{~m} / \mathrm{s}$

Figure 11: Instantaneous view of the predicted thermal plume with an average wind direction perpendicular to the fuselage. 


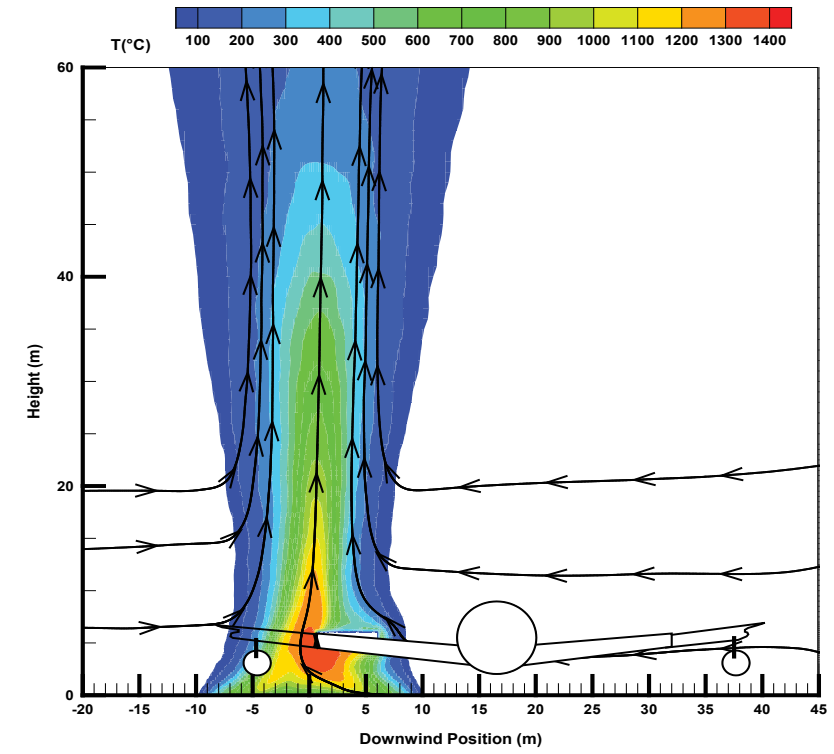

a) Aluminium-type

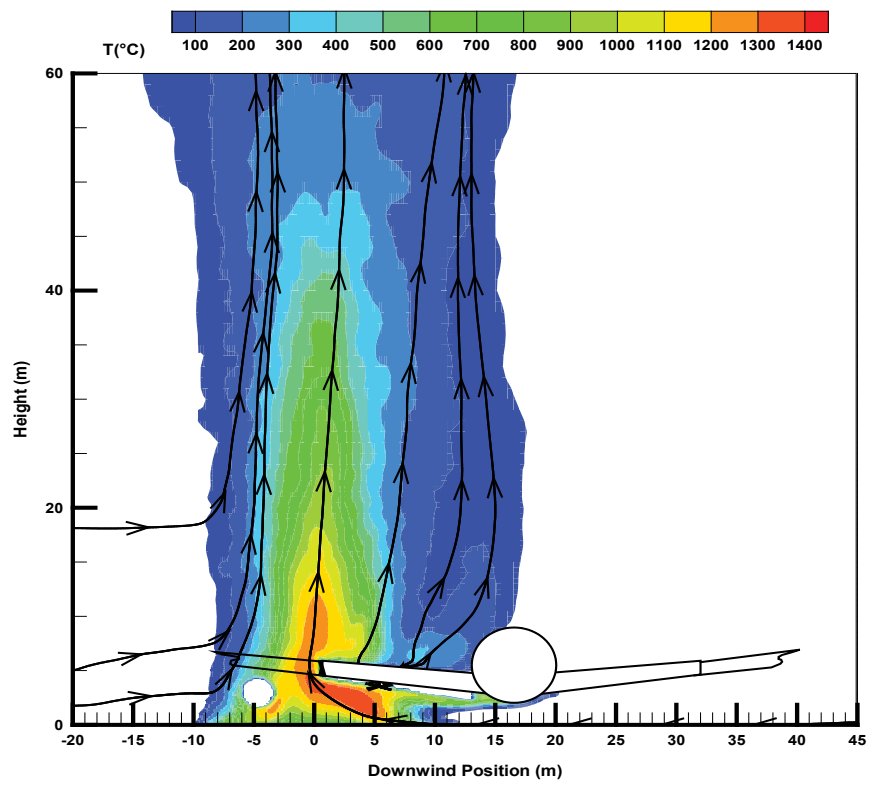

b) Composite-type

Figure 12: Contours of the time averaged temperature for fire containing an aircraft of aluminium- and composite-type under a quiescent condition.

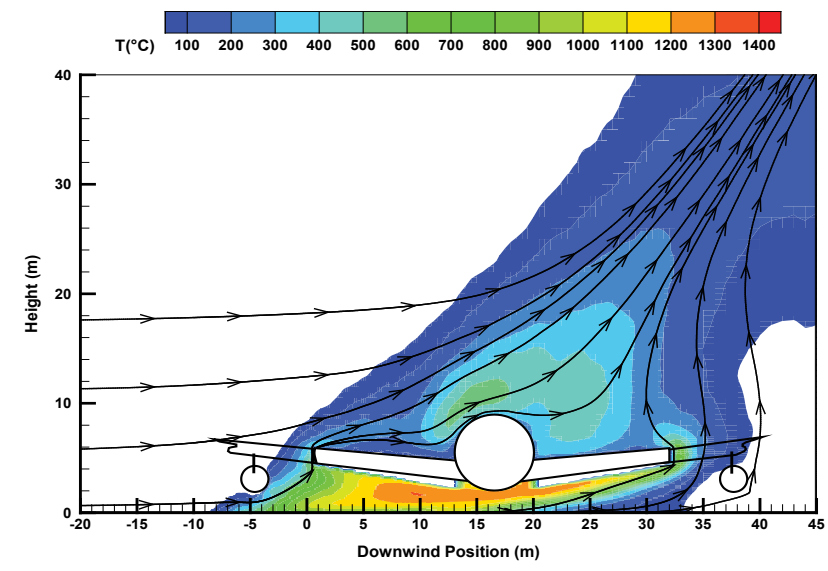

a) Aluminium-type

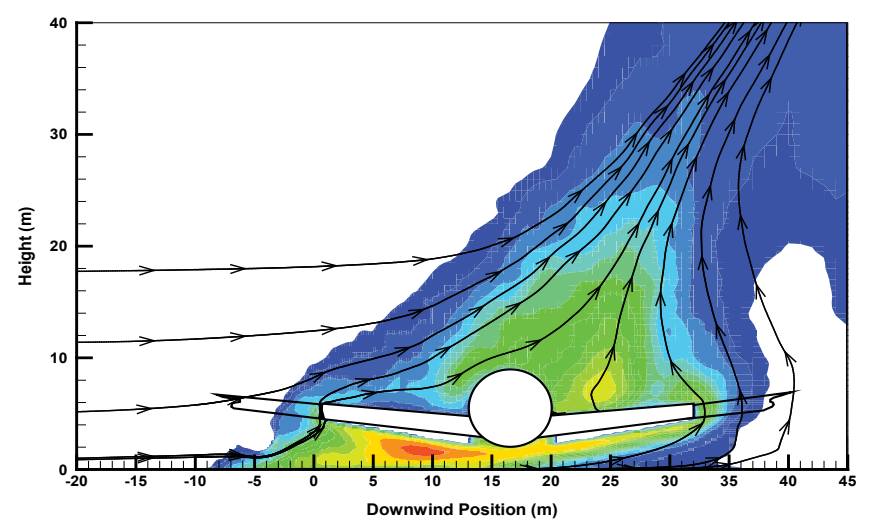

b) Composite-type

Figure 13: Contours of the time averaged temperature for fire containing an aircraft of aluminium- and composite-type for the medium wind speed of $U_{0}=5 \mathrm{~m} / \mathrm{s}$.

ed liquid pool fire with a diameter of $\mathrm{D}=20 \mathrm{~m}$, engulfing an aluminium- or composite-type aircraft is presented in Figure 12, Figure 13 and Figure 14. The time period over which the computation outputs were averaged from the last 60 seconds is considered as a quasi-steady period. The prediction suggests three main behaviors under a variety of wind conditions.

1. Under a quiescent condition (cf. Figure 12), the pool fire with a peak temperature of $1400{ }^{\circ} \mathrm{C}$ is located near the fuel source and far away from the aircraft. For the composite-type aircraft, there is an excess of fuel due to degradation of the composite material over the wing skin. This situation induces an increase in the thermal plume volume with time during the fire growth stage.
2. For the medium wind speed (cf. Figure 13 at $\mathrm{U}_{0}=5$ $\mathrm{m} / \mathrm{s}$ ), the flame is elongated in the downstream direction, and the region directly surrounding just in front of the aircraft is immersed in the highly combusting zone with a peak temperature of $1300^{\circ} \mathrm{C}$ due to complex wind/vorticity interactions. Flow is moving over the top of the aircraft creating streamwise vortices while fuel-rich air is forced below the fuselage. The composite-type aircraft induces an increase of the flame cover with a temperature level of about $700{ }^{\circ} \mathrm{C}$ on the upper leeward side of the aircraft. Besides, on the leeward side of the aircraft, the enhanced convective transport, as a whole, leads to a significant magnitude of temperature $\left(1300^{\circ} \mathrm{C}\right)$. 

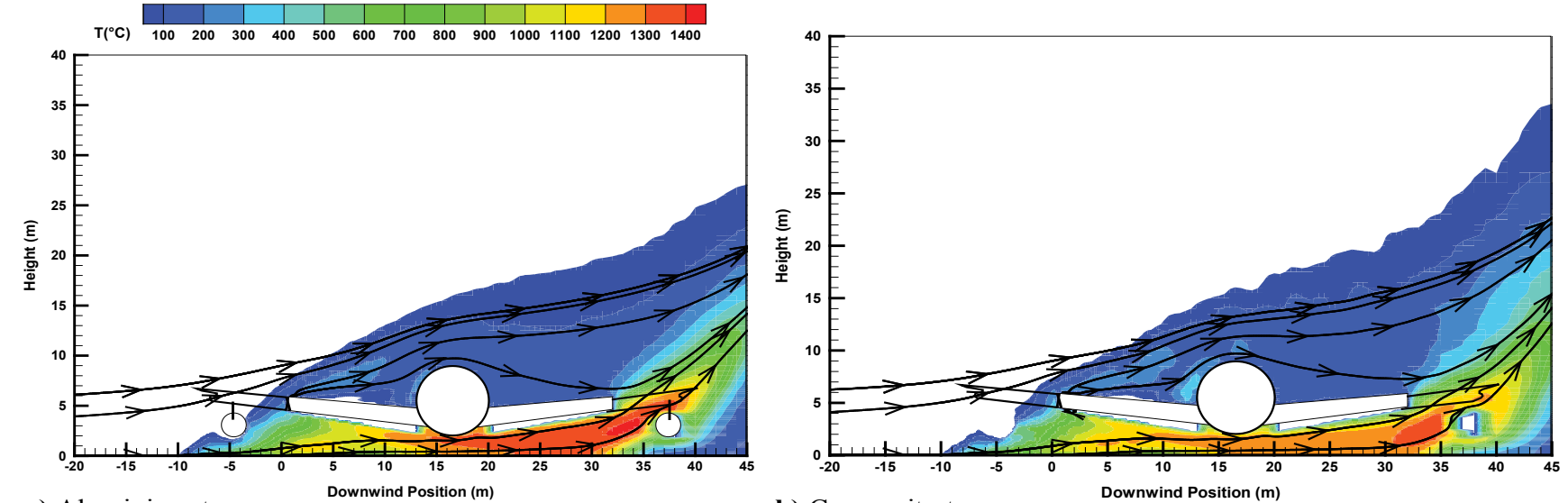

a) Aluminium-type

b) Composite-type

Figure 14: Contours of the time averaged temperature for fire containing an aircraft of aluminium- and composite-type for the high wind speed of $U_{0}=10 \mathrm{~m} / \mathrm{s}$.

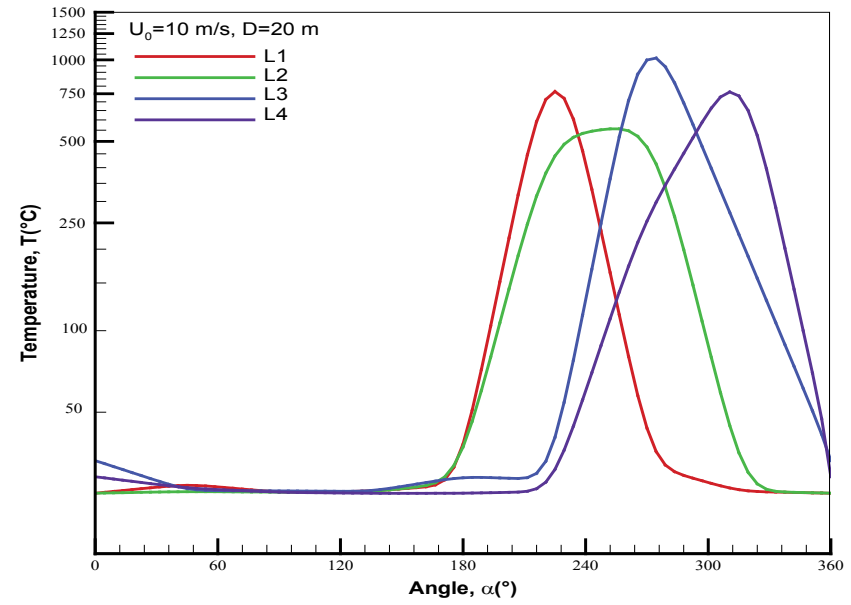

a) At the left door slides

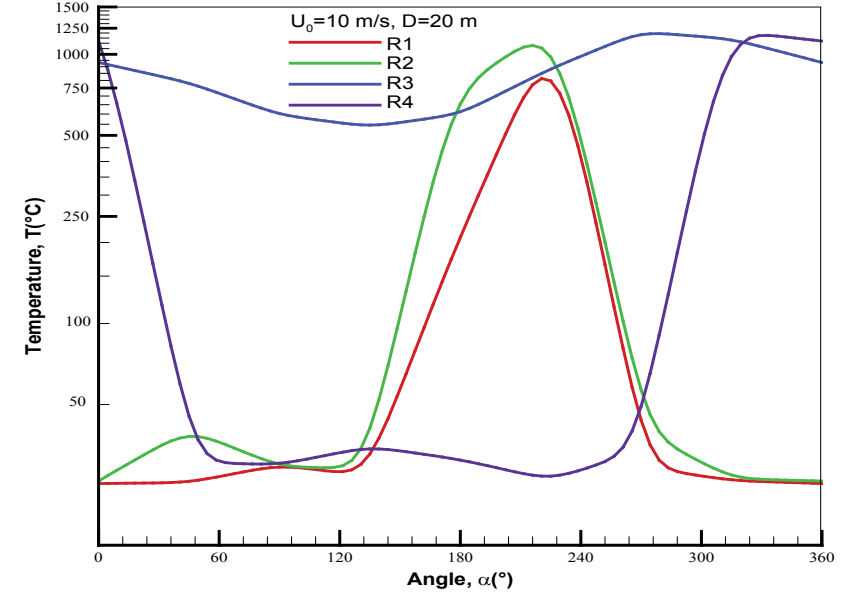

b) At the right door slides

Figure 15: Evolution of the predicted temperature at the left and right door slides as a function of the incident wind direction for an aluminium-type aircraft.

3. The high wind speed (cf. Figure 14 at $\mathrm{U}_{0}=10.2 \mathrm{~m} / \mathrm{s}$ ) enhances the interaction between the cross-flow and aircraft, and consequently, facilitates the global flame shape alterations. Besides, the fuel-rich flow is ejected from underneath of the aircraft, and this creates a second high temperature zone $\left(1400{ }^{\circ} \mathrm{C}\right)$ on the leeward side of the aircraft due to enhanced mixing by the presence of the vortices in the wake behind the aircraft. The magnitude of the wind speed is sufficient to direct the flame to the bottom surface of the fuselage, causing an excess of the fuel gas from the pyrolysis of the composite material there. Combustion beneath belly of fuselage is probably close to rich limit of flammability due to a decrease in the oxygen concentration there. Consequently, the presence of a composite-type aircraft (cf. Figure 14b) instead of an aluminium type one (cf. Figure 14a) results in a reduction in temperature of approximately $200{ }^{\circ} \mathrm{C}$ beneath belly of fuselage.
As an illustration, evolutions of the peak in temperature in the vicinity of each door as a function of the wind direction $\alpha$ defined in Figure 1 for a given wind speed of $10 \mathrm{~m} / \mathrm{s}$ are shown in Figure 15. The temperature levels at the left door slides appear negligible when the aircraft is upstream the pool fire $\left(\alpha<180^{\circ}\right)$. The left exits L1-2 will suffer significant damage with a high temperature level when the flame is directed towards the head of the aircraft $\left(180<\alpha<270^{\circ}\right)$. At the left exits L3 and L4, the temperature level appears significant when the wind direction is greater than $270^{\circ}$ corresponding to the case where the flame is directed towards the tail of the aircraft. The temperature level at the right door slides in the vicinity of the pool fire is rather sensitive to the wind direction even when the aircraft is upstream the pool fire $\left(\alpha<180^{\circ}\right)$. At the right exits R1 and R2, when the wind direction, $\alpha$, changes from $130^{\circ}$ to $270^{\circ}$, the thermal conditions are untenable. The right door slide $\mathrm{R} 3$ over the wing is immersed within the flame with the high temperature level in spite of the aircraft orientation. At the right door slide 


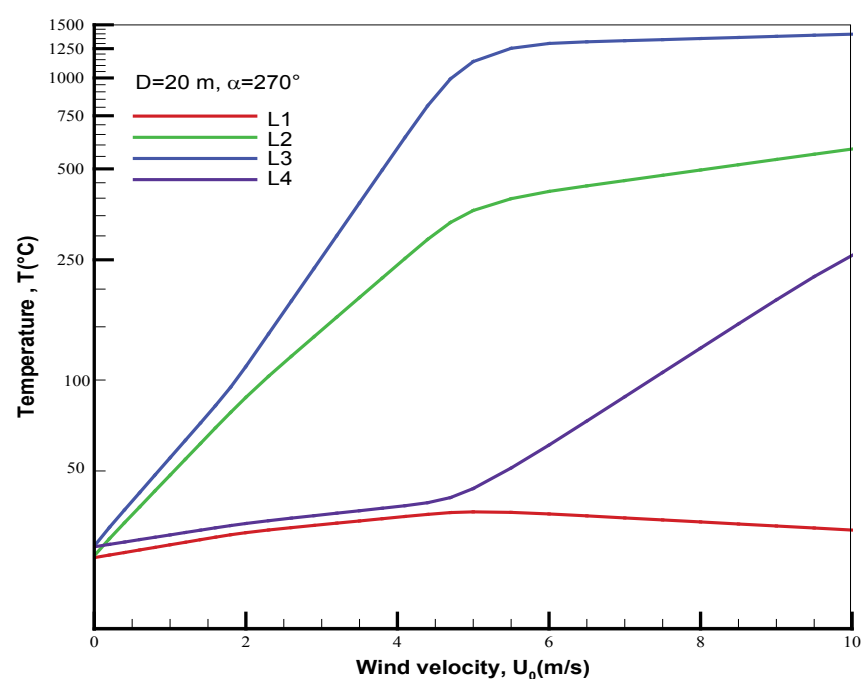

a) At the left door slides

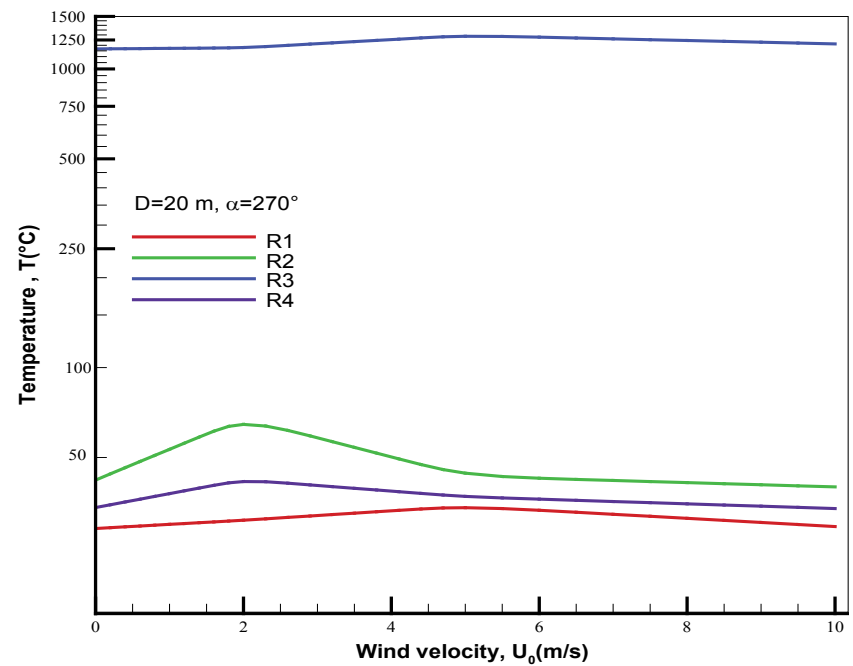

b) At the right door slides

Figure 16: Evolution of the predicted temperature at the left and right door slides as a function of the incident wind speed for an aluminium-type aircraft.

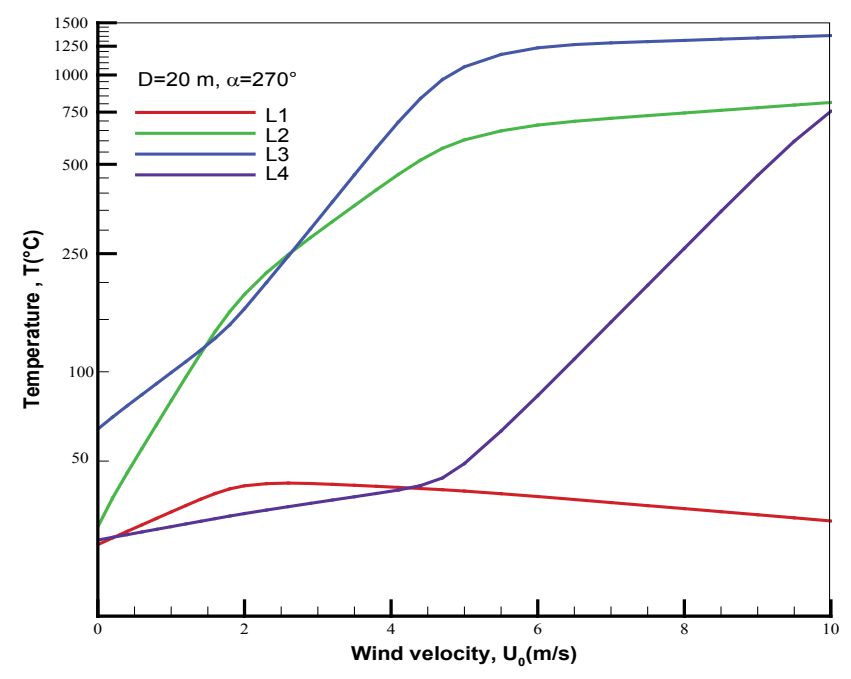

a) At the left door slides

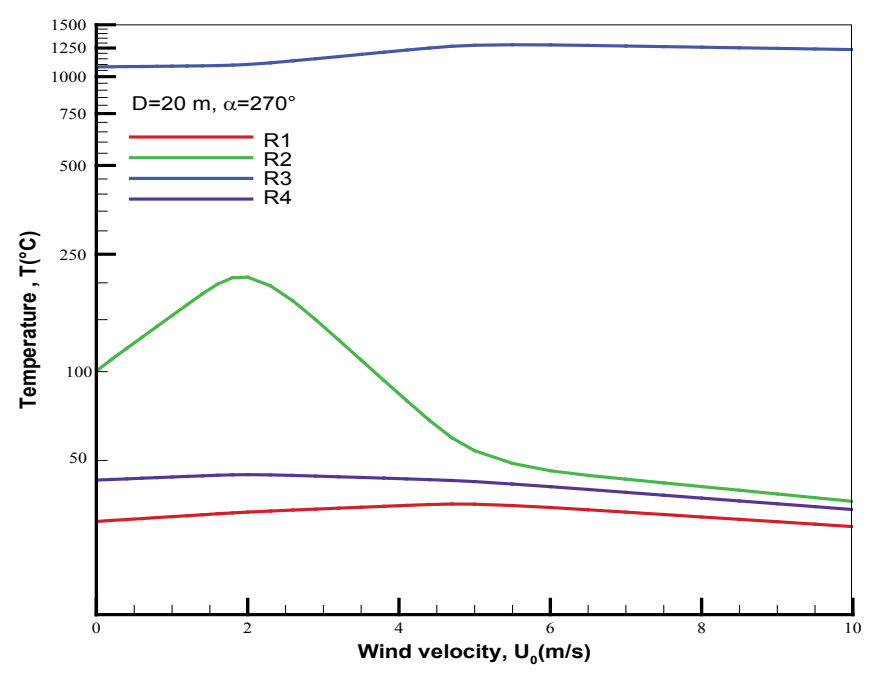

b) At the right door slides

Figure 17: Evolution of the predicted temperature at the left and right door slides as a function of the incident wind speed for a composite-type aircraft.

$\mathrm{R} 4$, the temperature level remains high when the flame is directed to the tail of the aircraft. Note that a similar distribution of the temperature at the door slides with the change of wind direction is observed for a composite-type aircraft.

Variation of the wind speed has also a pronounced impact on the temperature distribution in the vicinity of the door slides. The peak in temperature at the door slides of an aluminium-type aircraft as a function of the wind velocity is shown in Figure 16. As an illustration, only in the case where the wind direction is perpendicular to the aircraft moving direction is considered. Even in the case where the liquid pool fire $(\mathrm{D}=20 \mathrm{~m})$ is far away from the fuselage, the presence of wind induces a significant interaction between the flame, fuselage and wing. At the left door slide L1, the levels of temperature are effectively weak in spite of the wind speed. At the left door slides L2-4, the thermal conditions are untenable for the wind speed beyond $4 \mathrm{~m} / \mathrm{s}$. Flame propagation towards belly of fuselage exists due to impingement of the jet flame on the wing ceiling. Therefore, the right door slide R3 over the wing is immersed within the flame, and the magnitudes of the temperature appear remarkable in spite of the wind speed. Far away from the fire region, the magnitudes of temperature at the right door slides R1, R2 and $\mathrm{R} 4$ are found to be maintained at a weak level in spite of the wind speed. As shown in Figure 17, as compared to the aluminium-type aircraft, the presence of a composite-type one in fire does not change significantly the distribution of the temperature at the door slides for the low wind speed $\left(\mathrm{U}_{0}<4 \mathrm{~m} / \mathrm{s}\right)$. However, an increase of about 


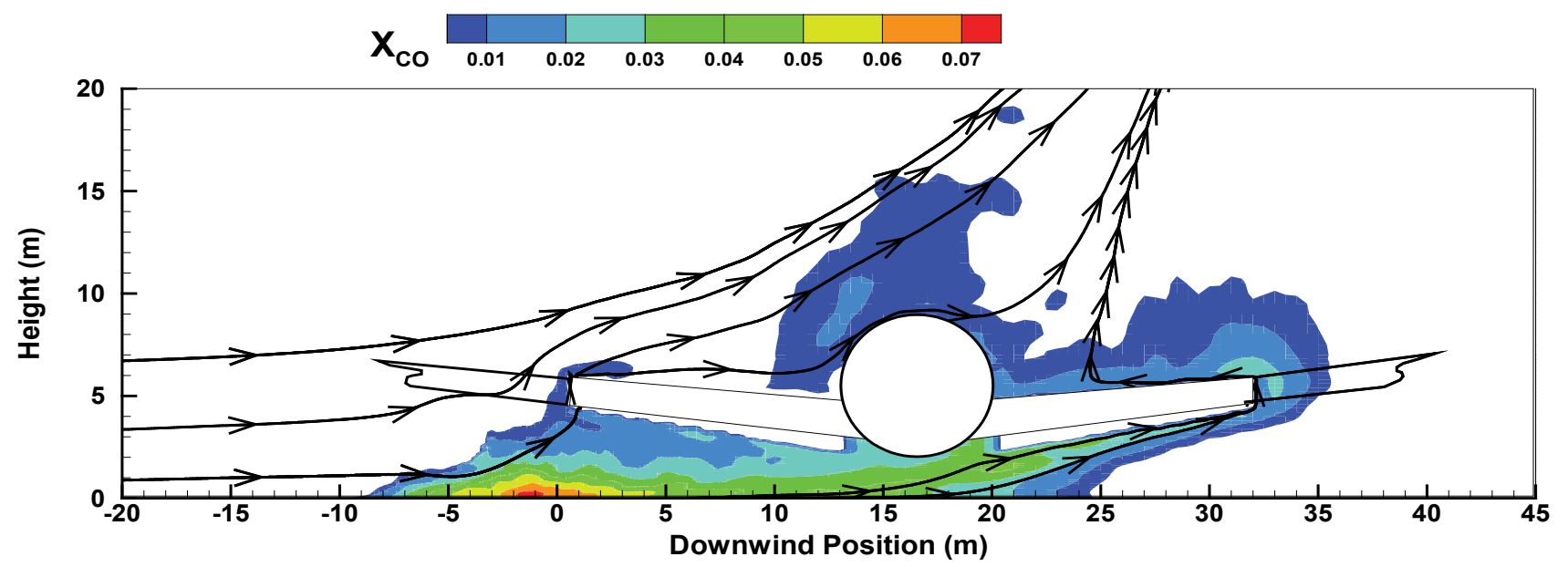

Figure 18: Contours of the time averaged $\mathrm{CO}$ molar fraction for fire containing a composite-type aircraft for the medium wind speed.

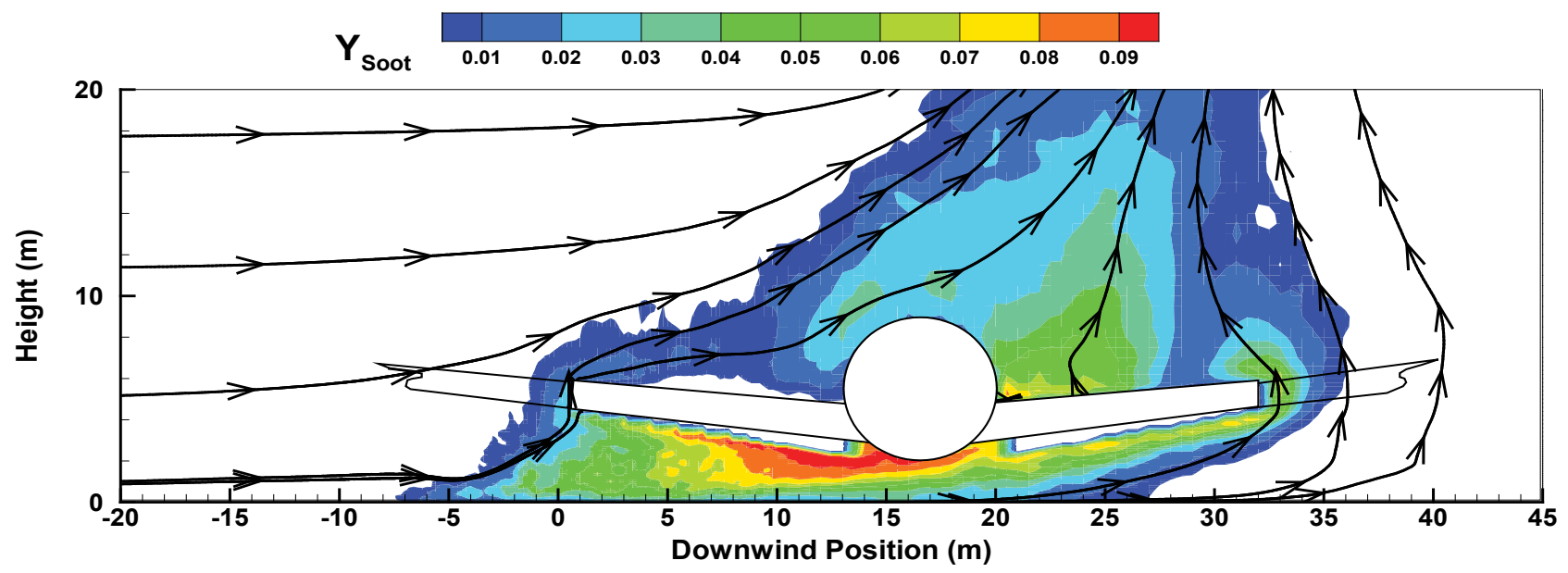

Figure 19: Contours of the time averaged soot mass fraction for fire containing a composite-type aircraft for the medium wind speed.

$200{ }^{\circ} \mathrm{C}$ in temperature level is induced by the presence of a composite-type aircraft at the left door slides L2 and $\mathrm{L} 4$ for the high wind velocity of $10 \mathrm{~m} / \mathrm{s}$. At the right door slide $\mathrm{R} 2$, the temperature level increases also from $60^{\circ} \mathrm{C}$ to $230^{\circ} \mathrm{C}$ for the low wind velocity of $2 \mathrm{~m} / \mathrm{s}$. This is mainly due to burning of the composite material over the skin of fuselage which enhances the radiation heat flux with increase of the flame volume.

Distribution of the toxic products: As an illustration, the time-averaged $\mathrm{CO}$ molar fraction and soot mass fraction on a wind-assisted liquid fire engulfing a composite-type aircraft for the medium wind speed are presented in Figure 18 and Figure 19. The primary flame zone contains large CO (cf. Figure 18) and soot (cf. Figure 19). On the leeward side of the aircraft, the enhanced convective transport, as a whole, leads to significant magnitudes of CO molar fraction (5\%) and of soot mass fraction (7\%). The fuel-rich flow is ejected from underneath of the aircraft, and this creates a second large $\mathrm{CO}$ and soot productions ( $10 \%$ in mass fraction) beneath belly of fuselage. Note that the presence of an aluminium-type aircraft in fire does not change significantly the distribution of the toxic products.

As an illustration, the peak in toxic releases as $\mathrm{CO}$ at the right and left door slides of the aircraft as a function of the wind velocity is shown in Figure 20 for the wind direction perpendicular to the fuselage. At the left door slide L1, the CO concentration appears negligible in spite of the wind speed. At the door slides L2-4, the peak in toxic products becomes significant for the wind speed beyond $4 \mathrm{~m} / \mathrm{s}$. The right door slide $\mathrm{R} 3$ over the wing is immersed within the flame, and the magnitude of the $\mathrm{CO}$ production appears remarkable in spite of the wind speed. Far away from the fire region, the CO concentration is found to be maintained at a low level. Thus, at the right door slides R1, R2 and R4, the peak in toxic 


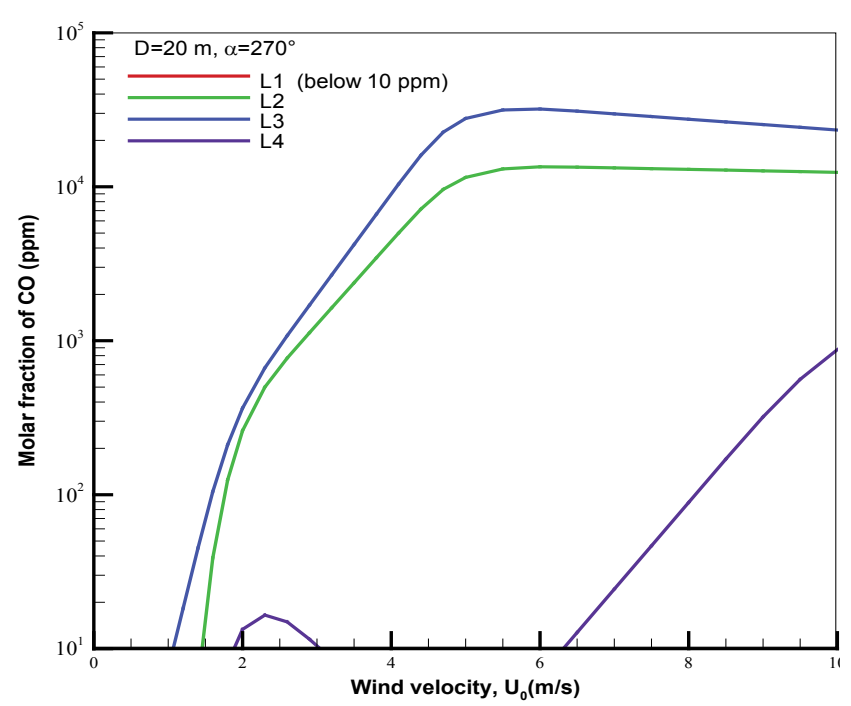

a) At the left door slides

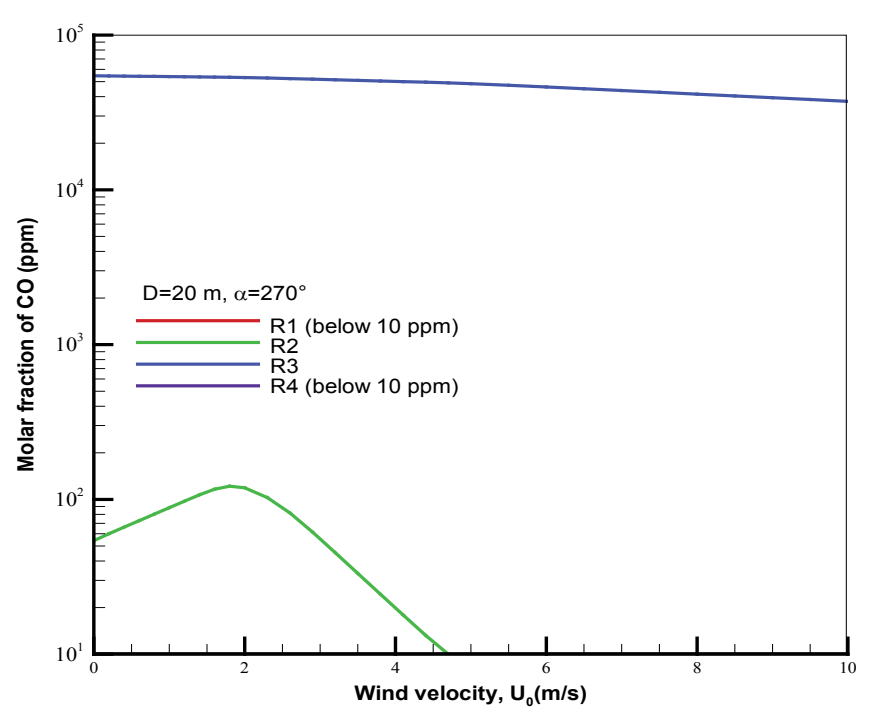

b) At the right door slides

Figure 20: Evolution of the predicted monoxide carbon at the left and right door slides as a function of the incident wind speed for an aluminium-type aircraft.

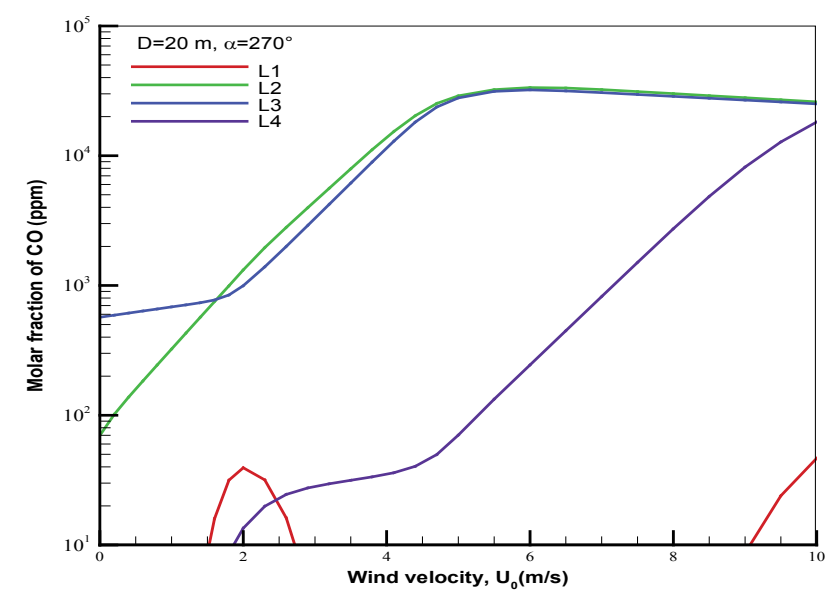

a) At the left door slides

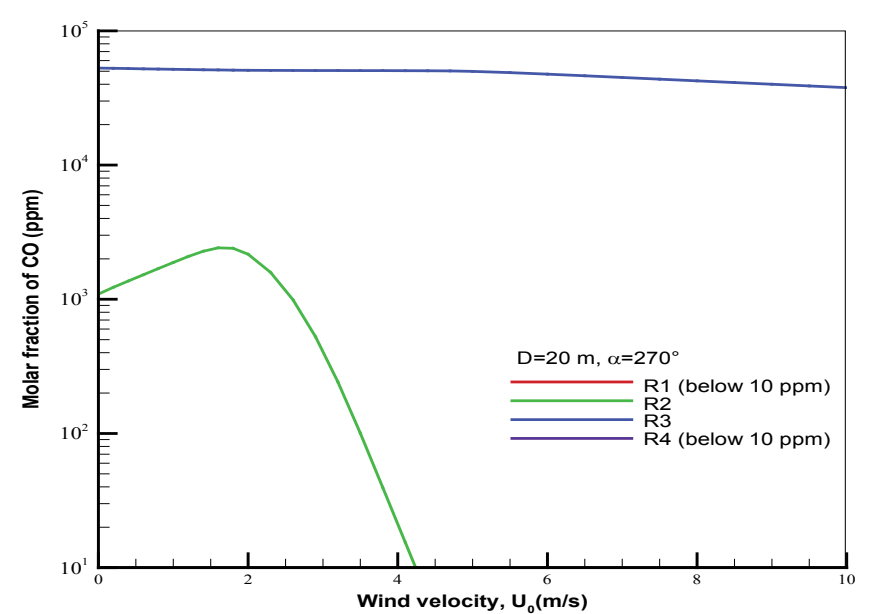

b) At the right door slides

Figure 21: Evolution of the predicted monoxide carbon at the left and right door slides as a function of the incident wind speed for a composite-type aircraft.

products appears negligible in spite of the wind speed. It should be noted that presence of a composite-type aircraft in fire (cf. Figure 21) does not modify significantly the distribution of the $\mathrm{CO}$ concentration at the door slides as compared to the aluminium-type one.

Distribution of the heat flux: Radiative heat transfer is combined with wind-enhanced, aircraft-induced turbulence and global flame zone redirection. The wind direction directly affects the view factor from the flame to the fuselage skin, and consequently, changes in the maximum heat flux to the fuselage and wing skin depend on the aircraft orientation. Interaction between the pool fire and the aircraft becomes stronger when the aircraft moving direction is perpendicular to the crosswind ( $\alpha$ $=270^{\circ}$ ) in particular for the wind speed beyond $5 \mathrm{~m} / \mathrm{s}$. If the aircraft moving direction is parallel to the wind direction, the cold air flow, which is believed to act as a radiation shield, exists between the pool fire and the fuselage, and there will be evidence of the lowest heat flux on the fuselage skin. Iso-contours of the predicted heat flux from the flame to the fuselage skin of an aluminum-type aircraft in the particular situation of $\alpha=270^{\circ}$ are illustrated in Figure 22 for a high speed of $10 \mathrm{~m} / \mathrm{s}$. The wind speed higher than $5 \mathrm{~m} / \mathrm{s}$ leads to a shallower smoke plume, and a region of increased heat flux to 340 $\mathrm{kW} / \mathrm{m}^{2}$ occurs only underneath the mock fuselage as a result of acceleration of the flow there creating a wellmixed region which can significantly strength the heat transfer. The peak in heat flux on the fuselage skin is below $30 \mathrm{~kW} / \mathrm{m}^{2}$ for the wind speed lower than $2 \mathrm{~m} / \mathrm{s}$. This is due to the fact that the pool fire is far away from the fuselage (about $25 \mathrm{~m}$ ), and the weak crossflow is deflect- 


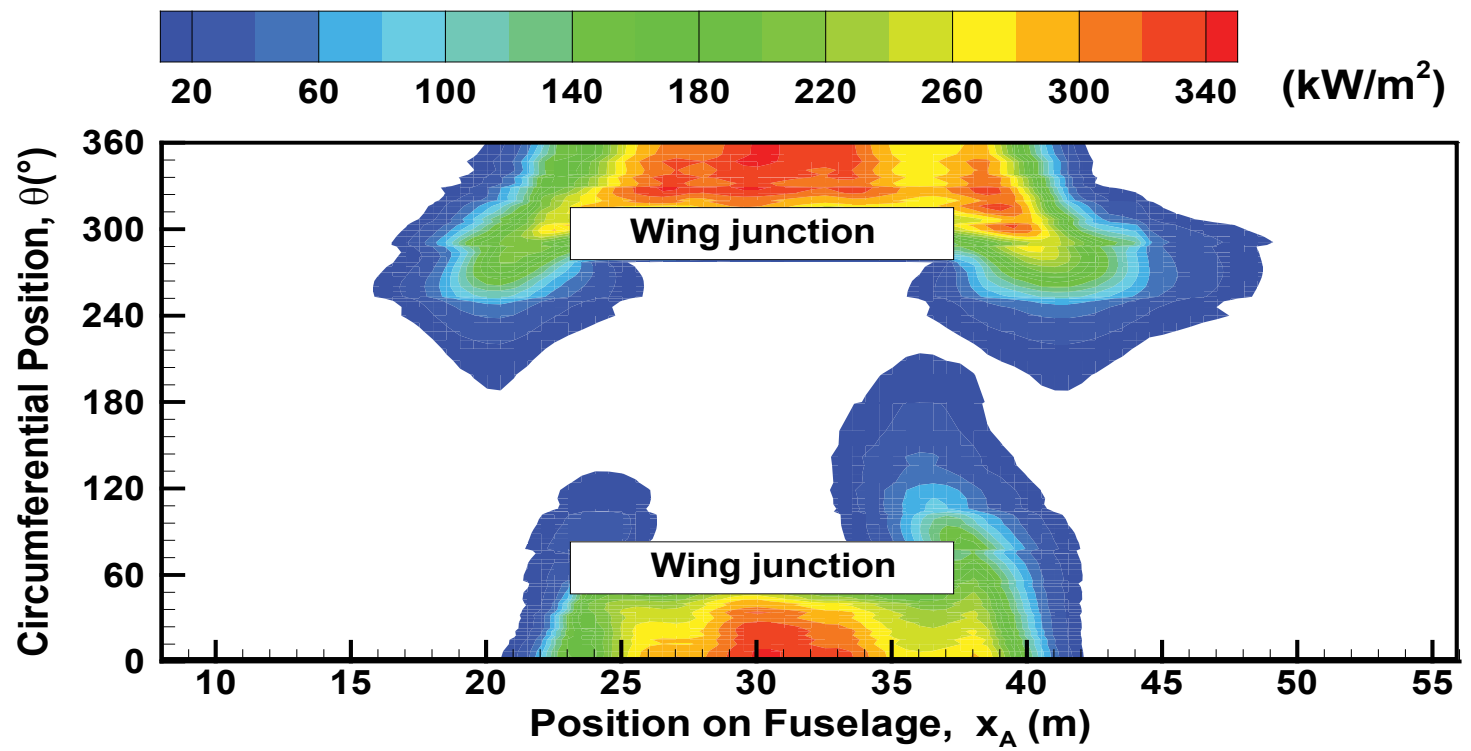

Figure 22: Iso-contour of the incident heat flux on the skin of the aircraft fuselage for $D=20 \mathrm{~m}, U_{0}=10 \mathrm{~m} / \mathrm{s}$ and $\alpha=270^{\circ}$.

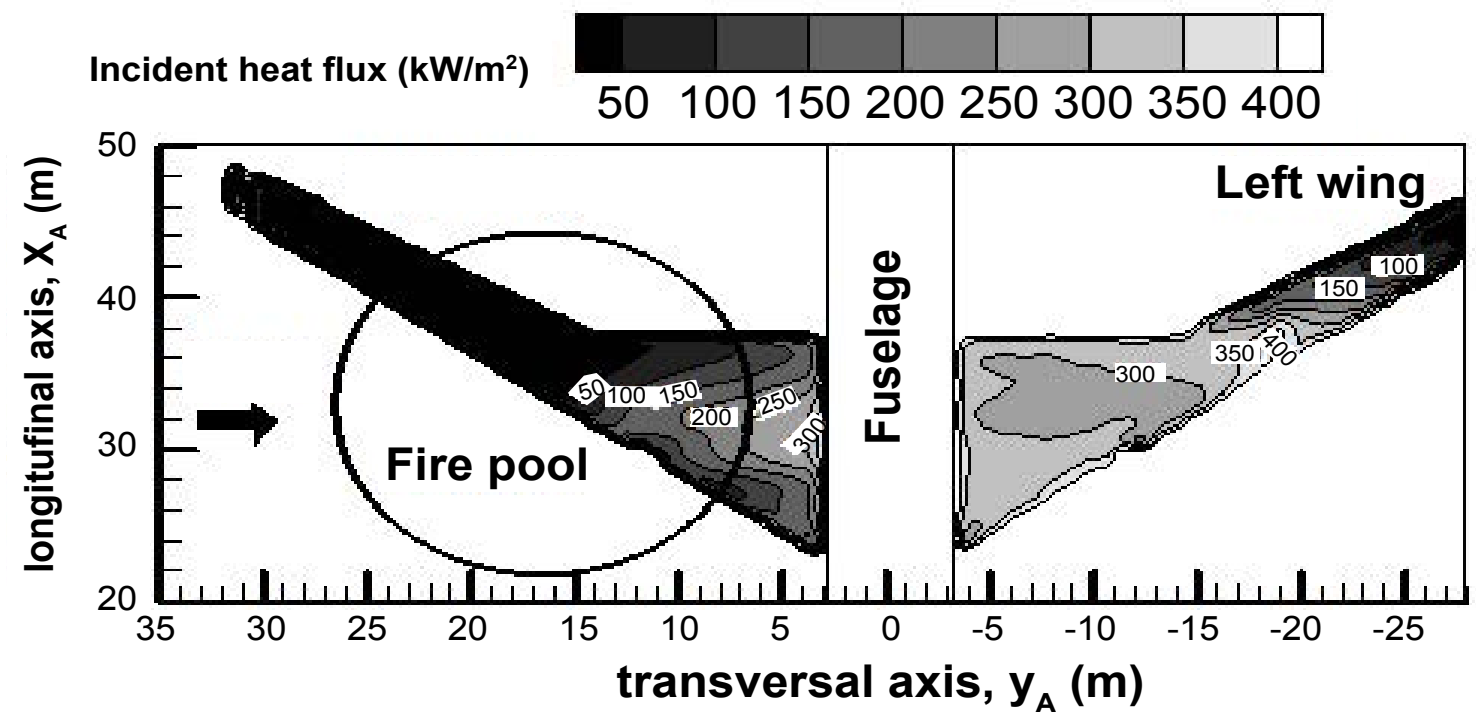

Figure 23: Iso-contour of the incident heat flux on the wings skin for $U_{0}=10 \mathrm{~m} / \mathrm{s}$ and $\alpha=270^{\circ}$.

ed by the buoyancy-induced air entrainment in the pool fire, preventing the flame from reaching fuselage. As illustrated in Figure 23, the extent of the higher heat flux to the wing skin rises with an increase of the wind speed to $10 \mathrm{~m} / \mathrm{s}$. The magnitudes of the heat fluxes in excess of $300 \mathrm{~kW} / \mathrm{m}^{2}$ exist over the two wings skin as a result of acceleration of a large flame base drag underneath the mock fuselage. Note that almost the same heat flux level exists over the skin of the composite-type aircraft. This situation significantly strengths the burning rate of the inflammable material, and induces a flame spread over the composite-type aircraft.

The peak in heat flux from the kerosene pool fire over the door skin as a function of the wind velocity is shown in Figure 24. Similar trend to the temperature distribu- tion (cf. Figure 7) at the door slides is found. The fact that the heat flux over the door skin is higher than $50 \mathrm{~kW} / \mathrm{m}^{2}$, indicates that an actively reacting region in the vicinity of door is present. It should be noted that if the doors, such as L2, L3 and R3 remain opening, uncontrolled postcrash fire in an intact fuselage will produce a flashover condition in the interior of cabin, which will be followed by a loss in survivability throughout the cabin.

\section{Conclusion}

The EDC-based combustion model and the common sub-grid scale turbulence model are satisfactory for the buoyancy-controlled, unconfined fire in crossflow. The CFD approach is much more realistic, when dealing with the characteristics of the wind-induced interaction of fires and large objects, than the simpler alternatives [13] 

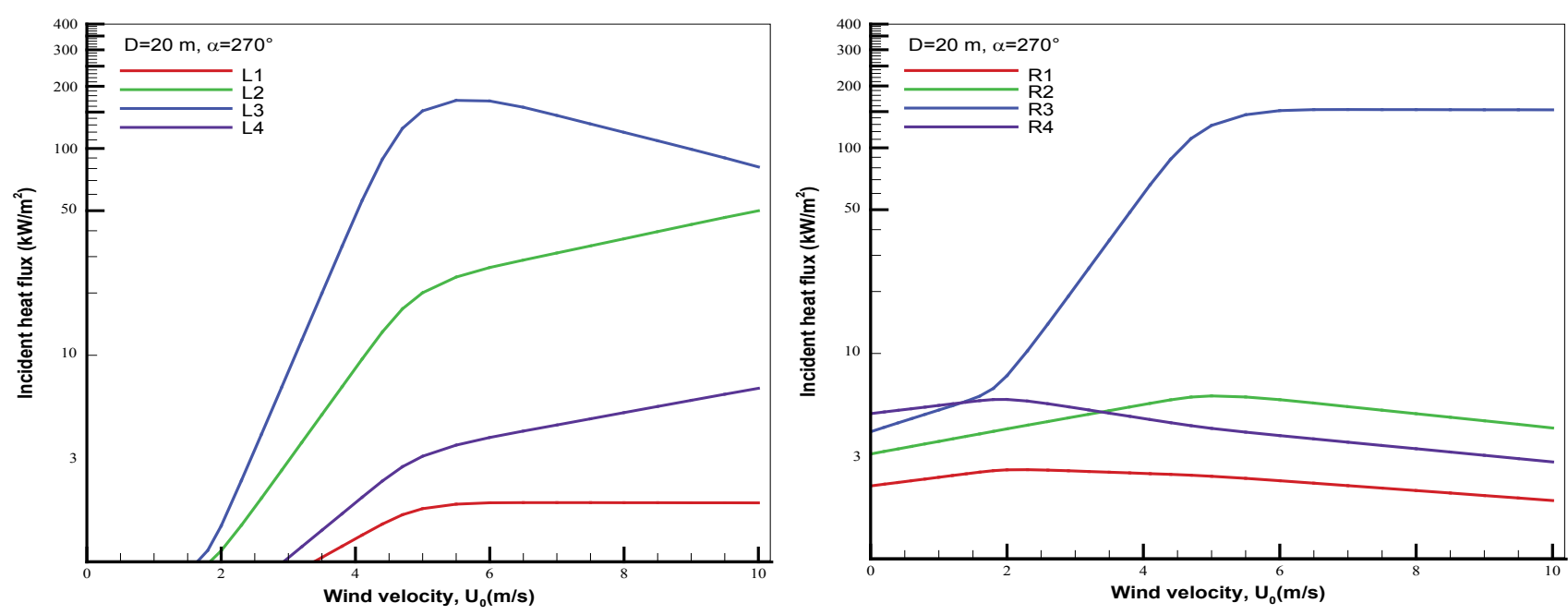

a) At the left doors skin

b) At the right doors skin

Figure 24: Evolution of the predicted peak in heat flux at the left and right doors skin as a function of the incident wind speed.

Table 1: Material property for the liquid fuel (kerosene) and the composite material.

\begin{tabular}{|l|l|l|}
\hline Property & Kerosene & $\begin{array}{l}\text { Composite } \\
\text { material }\end{array}$ \\
\hline Conductivity, $\mathrm{k}(\mathrm{W} / \mathrm{m} \cdot \mathrm{k})$ & 0.17 & 0.515 \\
\hline Density, $\rho(\mathrm{kg} / \mathrm{m} 3)$ & 750 & 1625 \\
\hline Heat capacity, $\mathrm{Cp}(\mathrm{kJ} / \mathrm{kg} \cdot \mathrm{k})$ & 2.45 & 2.015 \\
\hline Pyrolysis heat, $\mathrm{Lv}(\mathrm{kJ} / \mathrm{kg})$ & 256 & 9800 \\
\hline Combustion heat, $\mathrm{Hc}(\mathrm{kJ} / \mathrm{kg})$ & 44000 & 21000 \\
\hline Boiling temperature, $\mathrm{TB}\left({ }^{\circ} \mathrm{C}\right)$ & 216 & - \\
\hline Ignition temperature, $\operatorname{Tlgn}\left({ }^{\circ} \mathrm{C}\right)$ & - & 390 \\
\hline Emissivity, $\varepsilon$ & 1 & 0.9 \\
\hline
\end{tabular}

to guide the evacuation strategy. The worse scenarios are the significant elongation of the flame towards the aircraft in the downstream direction when the aircraft moving direction is perpendicular to the crosswind. There is evidence of the lowest heat flux or temperature on the doors of aircraft when the aircraft moving direction is parallel to the wind direction. Although the behavior is qualitatively correct, any attempt to draw quantitative conclusion is discouraged due to uncertainties introduced by large grid size which is primarily a problem of computational economy, and other idealizations inherent in the model.

This numerical study was conducted to supply information about the thermal exposure of a large object immersed in a fire environment. Activities have been confined to calculation of the gas temperature, and the heat flux on the fuselage and wing skin of aircraft. The peak in heat flux to the fuselage surface for various wind conditions ranges from $200-340 \mathrm{~kW} / \mathrm{m}^{2}$, and the contribution of radiation to the aircraft skin is higher than $95 \%$ of the total heat flux. The peak in heat flux over the fuselage skin to a medium or high wind is about a factor of 7 increases of that to a low wind speed. The largest factor affecting the reproducibility of the thermal and toxic environment in a large pool fire is the wind conditions. Increasing the wind leads to a shallower smoke plume, but does not help to suppress soot and CO around the engulfed aircraft.

The wind deviations in speed and direction are erratic in nature and contribute to the large spatial and temporal variations of the flame shape and heat flux. The natural constraints imposed by the wind deviation in its magnitude and direction prevent complete validation of this model. The disagreement between prediction and real fire situation may be due to the use of the average wind speed and direction in this numerical study. It would be highly desirable to relate the real wind conditions in the future investigation. Measurements, not only of temperatures and heat fluxes, but also the toxic product from a pool fire engulfing an aircraft, would consolidate the new insight provided by the CFD activity.

\section{Acknowledgements}

This study is sponsored by the European Project Aircraft Fire under Contract number FP7-2010-265612-CP.

\section{References}

1. Babrauskas V (1983) Estimating large pool fire burning rates. Fire Technol 19: 251-261.

2. Peatross MJ, Beyler CL (1997) Ventilation effects on compartment fire characterization. Fire Safety Science 5: 403414.

3. Utiskul Y (2006) Theoretical and experimental study on full-developed compartment fires. Fire Engineering, University of Maryland, USA.

4. Tewarson A, Lee JL, Pion RF (1981) The influence of oxygen concentration on fuel parameters for fire modelling. Symposium International on Combustion 18: 563-570.

5. Orloff La, d de Ris J (1982) Froude modelling of pool fires. Symposium International on Combustion 19: 885-895.

6. Novozhilov V (2001) Computational fluid dynamics model- 
ling of compartment fires. Prog Energy Combust Sci 27: 611-666.

7. Snegirev AY (2004) Statistical modelling of thermal radiation transfer in buoyant turbulent diffusion flames. Combust Flame 136: 51-71.

8. C Lautenberger, C Fernandez Pello (2009) Generalized pyrolysis model for combustible solids. Fire Safety Journal 44: 819-839.

9. JL Consalvi, Y Pizzo, B Porterie (2008) Numerical analysis of the heating process in upward flame spread over thick PMMA slabs. Fire Safety Journal 43: 351-362.

10. M Lavid, AL Berlad (1976) Gravitational effects on chemically reacting boundary layer flows over a horizontal flat plate. Sixteenth Symposium (International) on Combustion. Pittsburgh : The Combustion Institute, 1157-1167.

11. AA Putnam (1965) A model study of wind-blown free burning fires. Symposium International on Combustion 10: 1039-1046.

12. A Lonnermark, H Ingason (2006) Fire spread and flame length in large-scale tunnel fires. Fire Technology 42: 283302.

13. NR Keltner, W Gill, LA Kent (1994) Simulating fuel spill fires under the wing of an aircraft. Fire Safety Science 4: 10171028.

14. Greiner M, Suo Anttila A (2004) Validation of the Isis-3D computer code for simulating large pool fires under a variety of wind conditions. Journal of Pressure Vessel Technology, USA, 126: 360-368.

15. JM Suo Anttila, L Gritzo (2011) The effects of wind on fire environments containing large cylinders. Combustion Science and Technology, 181: 68-77.

16. BF Magnussen, IS Ertesvag (2000) The eddy dissipation turbulence energy cascade model. Combustion Science and Technology, 159: 213-235.

17. K McGrattan (2015) Fire Dynamics Simulator -Technical
Reference Guide. NIST Special Publication, 1018-1021.

18. T Beji, J Zhang, Delichatsios MA (2008) Determination of soot formation rate from laminar smoke point measurements. Comb Sci and Tech 180: 927-940.

19. K Himoto, T Tanaka (2004) A burning model for charring materials and its application to the compartment fire development. Fire Science and Technology 23: 170-190.

20. Murty Kanury (1984) Introduction to Combustion Phenomena. Gordon, New York.

21. N Djilali, I Gartshore, M Salcudean (1989) Calculation of convective heat transfer in recirculating turbulent flow using various near-wall turbulence models. Numerical Heat Transfer 16: 189-212.

22. YL Sinai, MP Owens (1995) Validation of CFD modelling of unconfined pool fires with cross-wind: flame geometry. Fire Safety J 24: 1-34.

23. HY Wang, H Sahraoui (2013) Mathematical modelling of pool fire burning rates in a full-scale ventilated tunnel. Proceeding of the 11th International Symposium on Fire Safety Science, Christchurch, New Zealand.

24. GD Wang, HY Wang, JM Most (2013) Mathematical modelling of the interaction between wind and aviation-fuel fire engulfing a fuselage-sized cylinder. Journal of Fire Sciences 31: 424-448.

25. (2006) Uncontained engine failure, Boeing 737-236 series 1, G-BGJL. Aircraft Accident Investigation Board (AAIB), United Kingdom.

26. E Lois, J Swithenbank (1979) Fire Hazards in Oil Tank Arrays in a Wind. Symposium International on Combustion 17: 1087-1098.

27. J Gregory, NR Keltner, R Mata (1989) Thermal measurements in large pool fires. Journal of Heat Transfer 111: 446454. 